NUREG/CR-3966

UCID-20639

\title{
Methods for Impact Analysis of Shipping Containers
}

T. A. Nelson, R. C. Chun

Prepared for

U.S. Nuclear Regulatory Commission

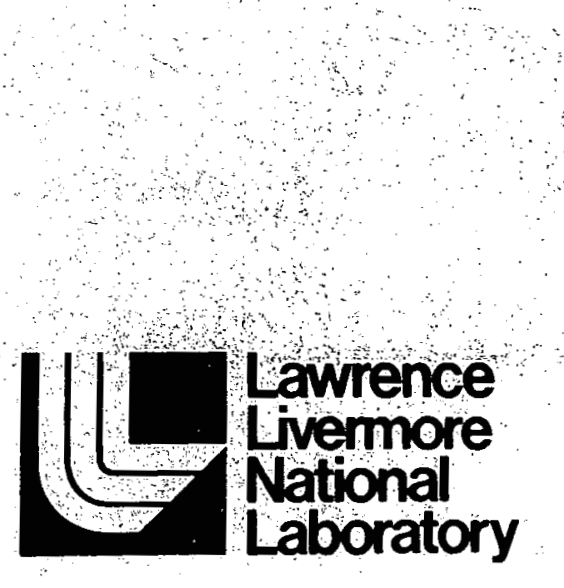

\section{DO NOT MICROFILM COVER}




\section{DISCLAIMER}

This report was prepared as an account of work sponsored by an agency of the United States Government. Neither the United States Government nor any agency Thereof, nor any of their employees, makes any warranty, express or implied, or assumes any legal liability or responsibility for the accuracy, completeness, or usefulness of any information, apparatus, product, or process disclosed, or represents that its use would not infringe privately owned rights. Reference herein to any specific commercial product, process, or service by trade name, trademark, manufacturer, or otherwise does not necessarily constitute or imply its endorsement, recommendation, or favoring by the United States Government or any agency thereof. The views and opinions of authors expressed herein do not necessarily state or reflect those of the United States Government or any agency thereof. 


\section{DISCLAIMER}

Portions of this document may be illegible in electronic image products. Images are produced from the best available original document. 


\section{NOTICE}

This report was prepared as an account of work sponsored by an agency of the United States Government Neither the United States Government nor any agency thereof, or any of their employees, makes any warraniy expressed or implied or assumes any legal liability of re sponsibility for any third party's use, or the results of such use, of any information apparatus, product or process disclosed in this report, or represents that its use by such third party would not infringe privately owned rights:
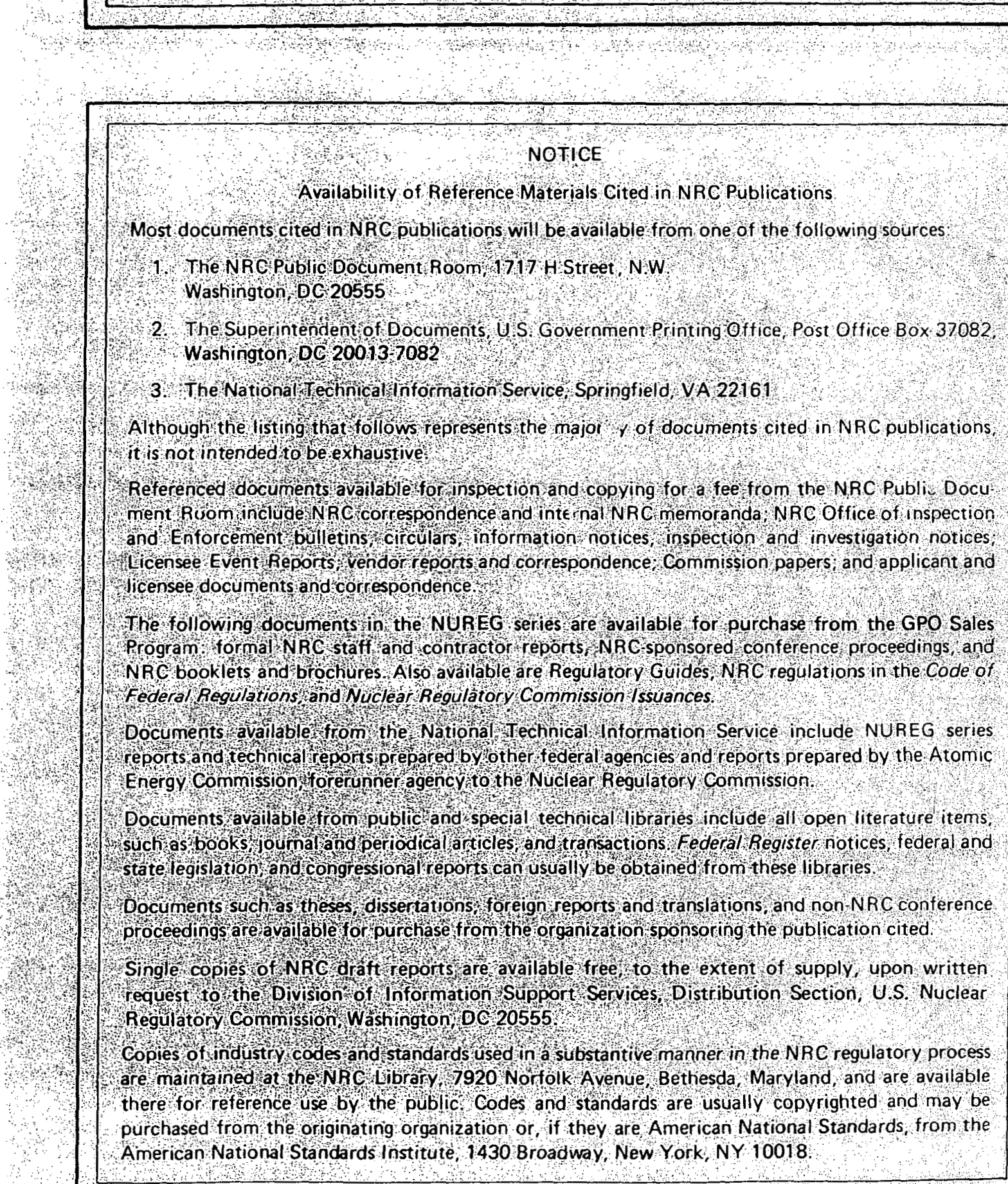
NUREG/CR-3966

UCID-20639

\section{Methods for Impact Analysis of Shipping Containers}

NUREG/CR--3966

TI88 002681

Manuscript Completed: October 1987

Date Published: November 1987

Prepared by

T. A. Nelson, R. C. Chun

Lawrence Livermore National Laboratory

7000 East Avenue

Livermore, CA 94550

Prepared for

Division of Safeguards and Transportation

Office of Nuclear Material Safety and Safeguards

U.S. Nüclear Regulatory Commission

Washington, D.C. 20555

NRC FIN No. A0291 


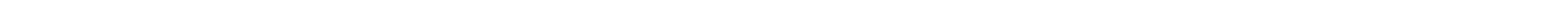




\begin{abstract}
This report reviews methods for performing impact stress analyses of shipping containers used to transport spent fuel. Three methods are discussed: quasi-static, dynamic lumped parameter and dynamic finite element. These methods are used by industry for performing impact analyses for Safety Analys is Reports.

The approach for each method is described including assumptions and limitations and modeling considerations. The effects of uncertainties in the modeling and analyzing of casks are identified. Each of the methods uses linear elastic structural analys is principles. Methods for interfacing impact stresses with the design and load combinations criteria specified in Regulatory Guides 7.6 and 7.8 are out lined.

The quasi-static method is based on D'Alembert's principle to substitute equivalent static forces for inertial forces created by the impact. The lumped parameter method is based on using a discrete number of stiffness elements and masses to represent the cask during impact. The dynamic finite element method uses finite element techniques combined with time integration to analyze the cask impact. Each of these methods can provide an acceptable means, within certain limitations, for analyzing cask impact on unyielding surfaces.
\end{abstract}

\title{
DISCLAIMER
}

\begin{abstract}
This report was prepared as an account of work sponsored by an agency of the United States Government. Neither the United States Government nor any agency thereof, nor any of their employees, makes any warranty, express or implied, or assumes any legal liability or responsibility for the accuracy, completeness, or usefulness of any information, apparatus, product, or process disclosed, or represents that its use would not infringe privately owned rights. Reference herein to any specific commercial product, process, or service by trade name, trademark, manufacturer, or otherwise does not necessarily constitute or imply its endorsement, recommendation, or favoring by the United States Government or any agency thereof. The views and opinions of authors expressed herein do not necessarily state or reflect those of the United States Government or any agency thereof.
\end{abstract}



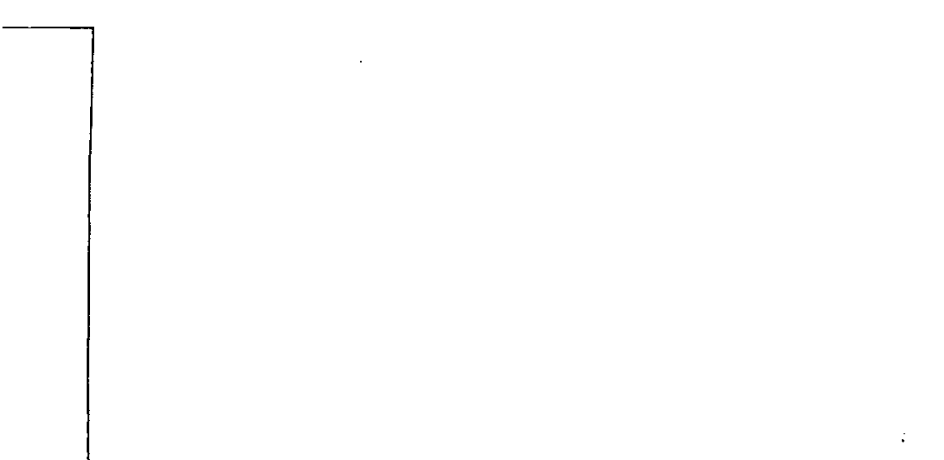


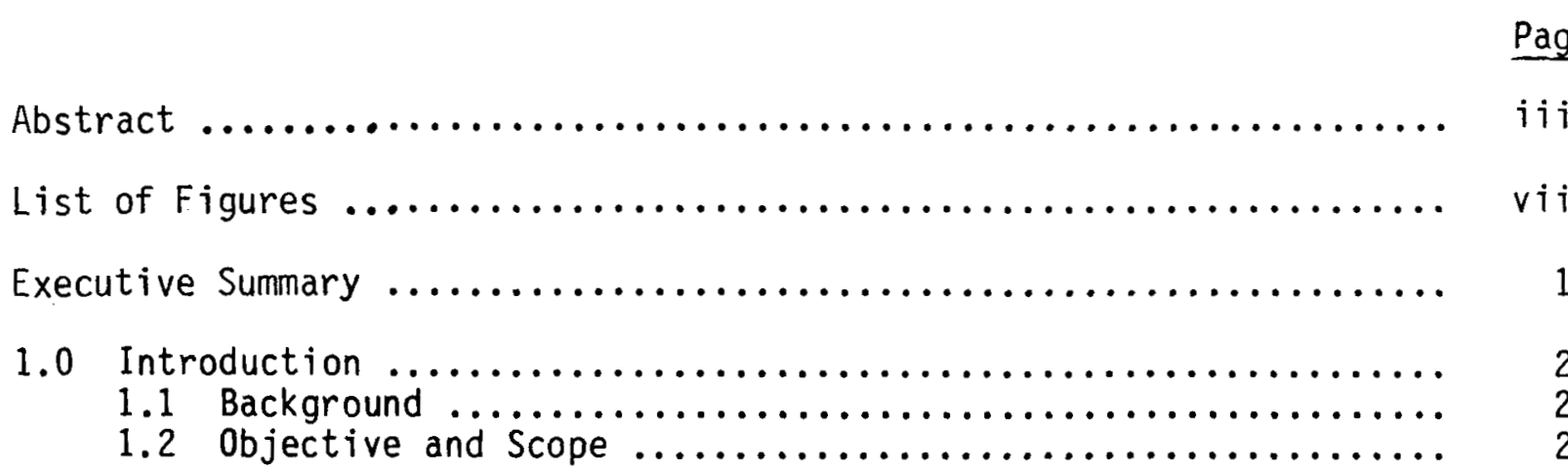

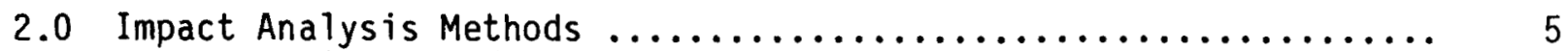

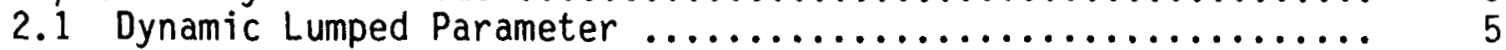

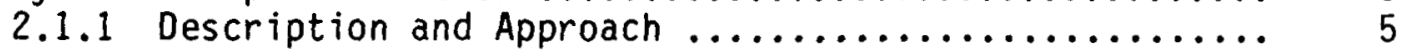

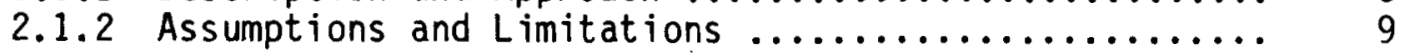

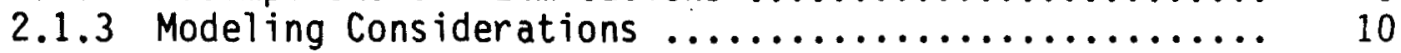

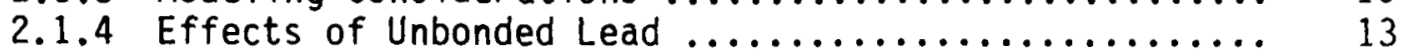

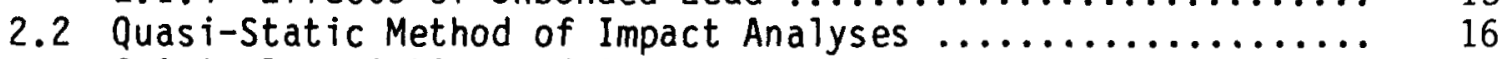

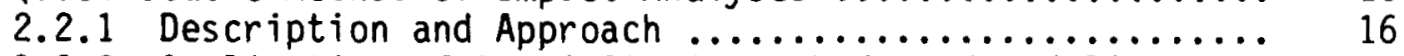

2.2.2 Application of Quasi-Static Methods and Modeling

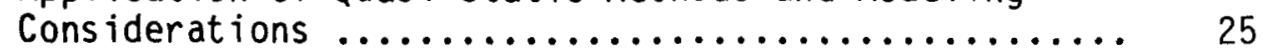

2.2.3 Limitations of Quasi-Static Methods .............. 28

2.3 Dynamic Finite Element Method of Impact Analyses ......... 31

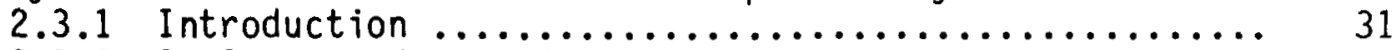

2.3.2 Analys is and Modeling Considerations ............. 31

2.3.3 Desirable Features of Computer Programs ........... 35

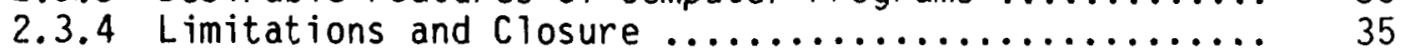

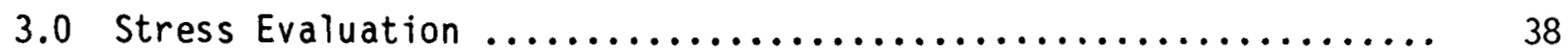

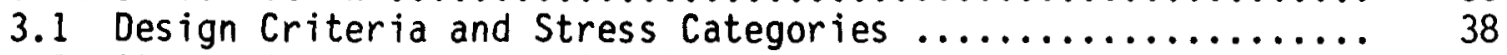

3.2 Stress Recovery From Simplified Models ................ 39

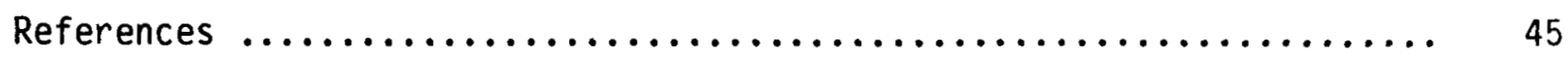

Appendix A - Internal Force Distribution in a Slender Rigid Beam .... A-1 


\section{List of Figures}

Fig. 1.1. Impact Analys is Methods Flow Chart.

Fig. 2.1. Maximum dynamic amplification factor (DAF) as a function of rise time for a ramp load on a single-degree-of-freedom system. (Ref. 5)

Fig. 2.2. Dynamic amplification factors for rectangular and triangular load shapes. (Ref. 5)

Fig. 2.3. Maximum dynamic amplification factor for a triangular load. (Ref. 5)

Fig. 2.4. Example cask model.

Fig. 2.5. Force-deflection curve of impact limiter.

Fig. 2.6. Postulated effective moment arms as a function of impact angle.

Fig. 2.7. Internal force distribution in a primary oblique impact.

Fig. 2.8. Coordinate systems for oblique drops.

Fig. 2.9. Schematic of oblique impact.

Fig. 2.10. Internal force distribution in a secondary obrique impact.

Fig. 2.11. Internal axial force in an end-on impact.

Fig. 2.12. Geometric parameters important to C.G. drop.

Fig. 2.13. Loading as a result of side impact.

Fig. 2.14. Response to a suddenly applied step function (from Fig. 5.9-2 of Ref. 10).

Fig. 2.15. Amplification factor for a half-sine wave (from Fig. 4-5 of Ref. 11).

Fig. 2.16. Example of three dimensional finite element mesh (from Ref. 20).

Fig. 3.1. Load Combinations and Stress Intensity Limits.

Fig. 3.2. Stress recovery for solid and laminated casks.

Fig. 3.3. Typical cask closure configurations and associated analytical models. 
Fig. A.1.

Fig. A.2.

Fig. A.3.
Coordinate systems for oblique drops of slender rigid beam. Equilibrium of slender rigid beam in the longitudinal direction.

Equilibrium of slender rigid beam in the lateral direction. 
is

\section{FOREMORD}

As part of their charter to license spent fuel shipping casks, the U.S. Nuclear Regulatory Commission must evaluate the structural adequacy of the container under a series of postulated loading conditions. Industry has several options availabie for performing analyses to ensure structural adequacy under impact loading. The purpose of this report is to evaluate the available options and describe acceptable methods for performing impact analysis.

The authors would like to acknowledge the assistance of L.E. Fischer, Lawrence Livermore National Laboratory, for his advice during the compilation of this report. 


\section{EXECUTIVE SUMAARY}

To protect the public health and safety, designs of casks used to ship spent nuclear fuel are required to be evaluated for impacts on unyielding surfaces under conditions of normal transport and hypothetical accident conditions. The conditions under which the casks must perform are specified in 10 CFR 71. Acceptable means for showing acceptable performance are delineated in U.S. Nuclear Regulatory Commission (USNRC) Regulatory Guides 7.6 and 7.8 .

Several different methods are used by the shipping cask industry to perform impact analyses of casks. The purpose of this report is to review three commonly used methods, evaluate their applicability, discuss appropriate modeling techniques and describe assumptions and limitations of each method. The results of the review are intended to assist the USNRC in evaluating the appropriateness of licensee submittals.

The methods reviewed in this report are: quasi-static, dynamic lumped parameter, and dynamic finite element. Each method can be used to predict the response of a cask to impact load under certain conditions. The dynamic analysis methods can more accurately predict cask response under impact loading since this loading produces dynamic response in the cask.

The quasi-static method is based on D'Alembert's principle to substitute equivalent static forces for inertial forces created by impact. This method treats the cask as a slender rigid bar and cannot capture dynamic cask response. Also, restrictive assumptions must be applied to capture secondary impact. It is not recommended for analyzing oblique impact cases.

The dynamic lumped parameter method combines simplicity in modeling with the ability to capture dynamic cask response as a result of the rapid impact load. In addition, the method can be formulated to capture the rigid-body rotation which can occur as a result of oblique impact. Overall cask response can be determined as well as the resulting major stresses. Stress recovery assumptions can start to become restrictive if calculation of detailed stress states is attempted. A computer code employing a dynamic lumped parameter method, called IMPASC (Impact Analys is of Shipping Casks), has been developed by the Lawrence Livermore National Laboratory as part of an integrated shipping cask analysis system. In IMPASC; the cask is modeled as a series of beams with masses lumped at the nodes. Currently, casks with lead shielding are modeled with composite beam properties, which assumes that the lead is bonded to the steel shells.

In order to obtain detailed stress recovery or model nonlinear behavior, such as lead slump, a dynamic finite element analysis should be used. In this method, each component can be modeled separately and stresses in each element can be calculated directly during the analysis. While they can be expensive and time consuming, dynamic finite element analys is methods can provide the most accurate and detailed estimates of cask response to impact loads. 


\subsection{INTRODUCTION}

\subsection{BACKGROUND}

To protect the public heaith and safety, shipments of spent fuel are required to be in accordance with the provisions of 49 CFR 171-178 (Ref. 1) and 10 CFR 71 (Ref. 2). All activities, which are related to the design, fabrication and use of spent fuel casks are documented in a safety analysis report (SAR) and conducted under a quality assurance program, both of which are reviewed and approved by the U.S. Nuclear Regulatory Commission (NRC). Regulations in 10 CFR 71 , Sections .71 and .73 require that the design of spent fuel casks be evaluated for impacts on unyielding surfaces for normal transport and hypothetical accident conditions.

Regulatory Guides 7.6 (Ref. 3) and 7.8 (Ref. 4) provide acceptance criteria for elastic stress analysis limits and load combinations for the containment system. Several different methods of analys is are currentiy used by the shipping cask industry to evaluate spent fuel cask designs. A complete description of the impact method used in analyzing a cask design is required in the SAR. This NUREG discusses three commonly used methods for performing analysis for spent fuel casks impacting onto unyielding surfaces. In Fig. 1.1, a flow chart is presented showing the major elements in each method of analysis.

A survey was performed to identify methods used by industry for performing impact analyses to evaluate the structural integrity of shipping casks. Information and methods were determined from industry reports, SARs and communication with industry personnel. The acceptance criteria of Regulatory Guides 7.6 and 7.8 were reviewed to assure that the impact analysis methods selected for discussion would result in compliance with these guides. A procedure was outlined for combining and post processing linear elastic stress analysis results to permit the comparison of those results with the stress acceptance criteria specified in R.G. 7.6. Procedures were also described for separating stresses into membrane and bending components and into their appropriate stress categories. These general procedures will be discussed in the following sections.

\subsection{OBJECTIVE AND SCOPE}

The objective of this work was to document methods for analyzing shipping containers for the impact loads specified in 10 CFR 71. For each analytical method, the report discusses appropriate techniques for modeling the structure and the reasonableness of various assumptions that can be used to facilitate the analysis.

The scope of the discussion was as follows:

1. Impact analys is methods were identified which could reasonably, yet conservatively, predict spent fuel cask containment stresses for 


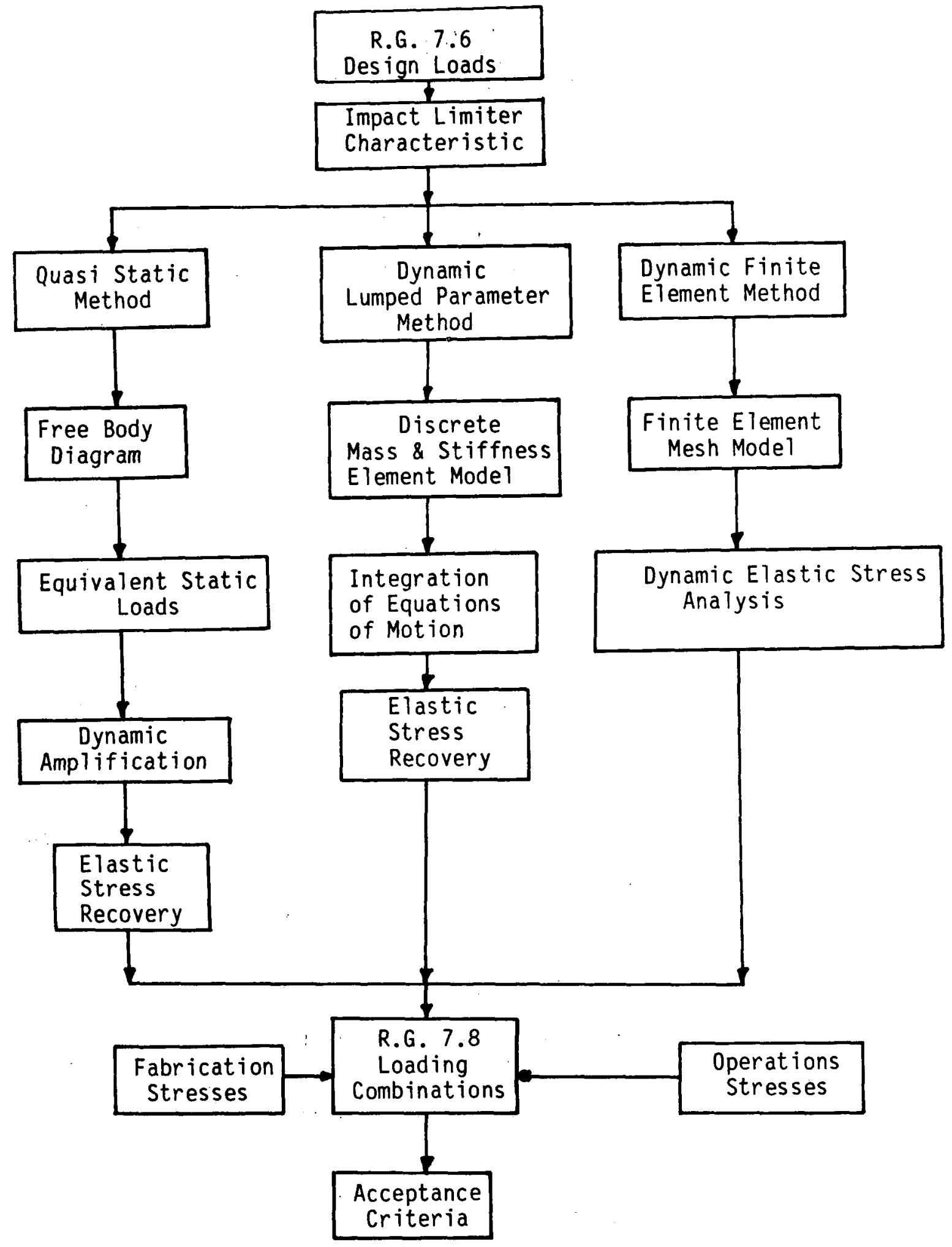

Fig. 1.1 Impact Analysis Methods Flow Chart. 
comparison with the elastic limits and criteria presented in Regulatory Guides 7.6 and 7.8. Since on $7 y$ containment is considered, stresses in internals were not included.

2. The analyses discussed herein presume elastic behavior such that principles of superposition apply for the purposes of combining loads. Buckling of the containment was not considered.

3. Modeling techniques including assumptions and approximations employed for three basic types of analyses were evaluated.

4. The spent fuel cask contents were included only as inertial loads and boundary conditions.

5. Brittle fracture effects were not considered.

6. Techniques for analyzing stresses in closures and their associated bolting under impact were developed.

7. The interaction between shielding and containment materials (e.g., lead slump) under impact were discussed for certain cases. 


\subsection{IMPACT ANALYSIS METHODS}

\subsection{DYMAMIC LUMPED PARAMETER}

\subsubsection{DESCRIPTION AND APPROACH}

The dynamic lumped parameter approach is used to provide analytical results that account for the dynamic response of the cask as well as the rigid body motion associated with oblique impact. The cask geometry is modeled in one dimension. This model consists of a series of lumped masses connected by springs, beam elements, or other specialized elements.

The primary purpose of the lumped parameter model is to capture the overall response of the cask. Since this model is used in a dynamic analys is, it is superior to a quasi-static approach in that dynamic effects are accounted for. The basic dynamic amplification phenomenon can be illustrated by means of a simple, one-degree-of-freedom system which might approximate an end-on impact of a cask. The dynamic amplification factor (DAF) is equal to the dynamic deflection divided by the deflection caused by a statically applied load of the same magnitude (Ref. 5). The DAF is a function of the rise time of the applied load, the duration of the load, the shape of the load, and the natural period of the structure. To illustrate the effect of rise time, 'Fig. 2.1 shows the maximum DAF as a function of rise time for a ramp load. For an infinitesimal rise time, the maximum DAF is 2.0. Thus, the maximum deflection, and the corresponding force in the spring, is twice that for a statically applied load.

The effects of load duration and, to some extent, load shape are shown in Fig. 2.2. The two loads shown in the figure have an infinitesimal rise time. As shown in the figure, load duration, as compared to the natural period of the system, has a large effect on the magnitude of the DAF. For a load duration less than one half of the system period, the DAF is less than 2.0 and can be less than 1.0 .

In general, an impact load experienced by a cask will show the effects of both finite rise time and duration. An example for a triangular pulse is shown in Fig. 2.3. For this particular load shape, the maximum DAF would be 1.5 .

When modeling a three-dimensional structure as a simple lumped-mass system, simplifying assumptions need to be used. For end-on impact only, multi-dimensional effects may be avoided by only allowing axial degrees of freedom in the models. For these models, the cask is discretized into a number of elements. Each node is assigned a mass and each element a spring stiffness. In some computer programs (e.g, Ref. 6), these stiffnesses are calculated externaliy to the code. Plane sections of the cask are assumed to remain plane and normal to the centerline of the cask. Thus, the lead shielding is assumed to experience the same deflection as the steel shells which surround it. In effect, this model assumes perfect bonding between the lead and steel for the axial case. For bending, composite stiffness of 


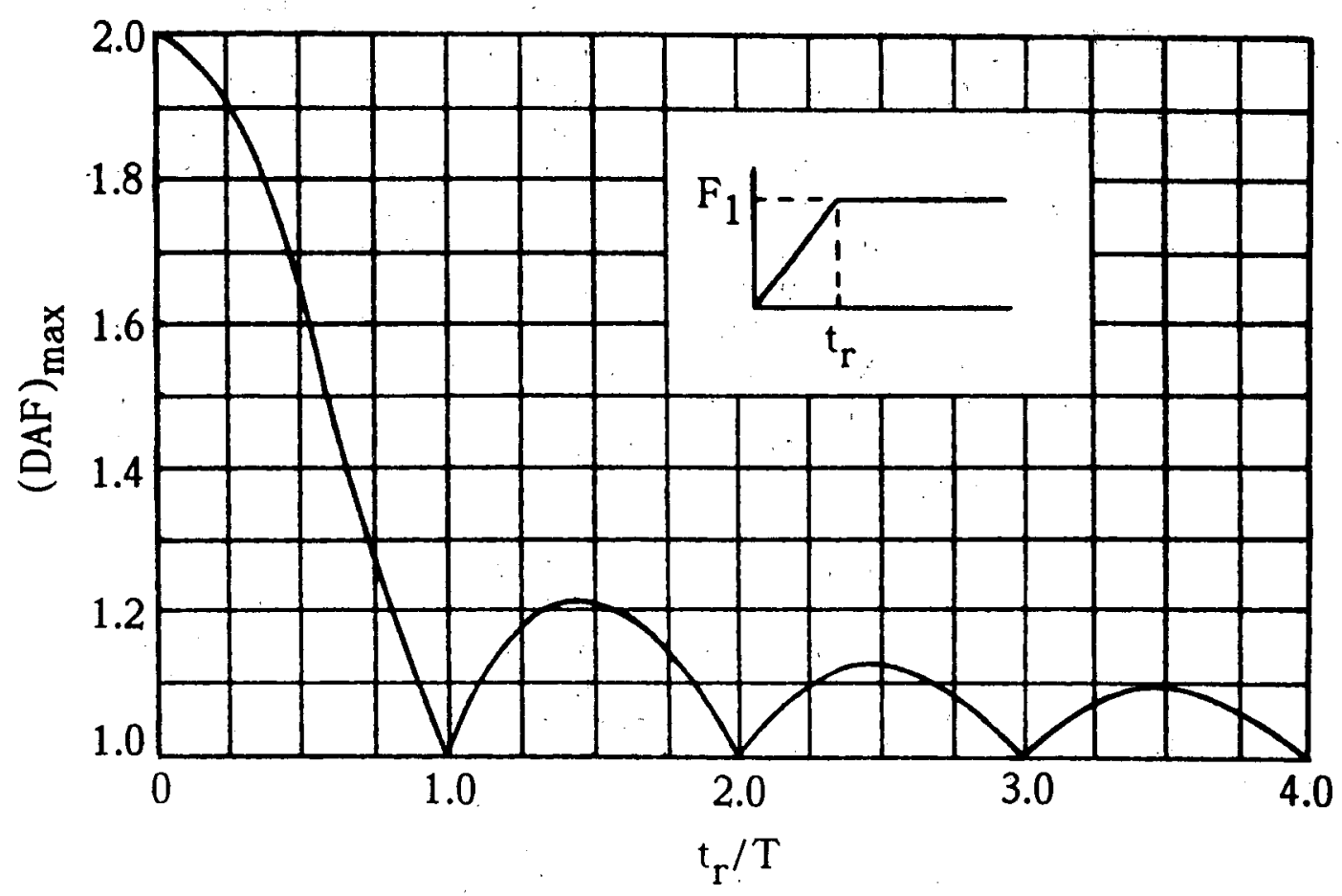

Fig. 2.1. Maximum dynamic amplification factor (DAF) as a function of rise time for a ramp load on a single-degree-of-freedom system. (Ref. 5) 


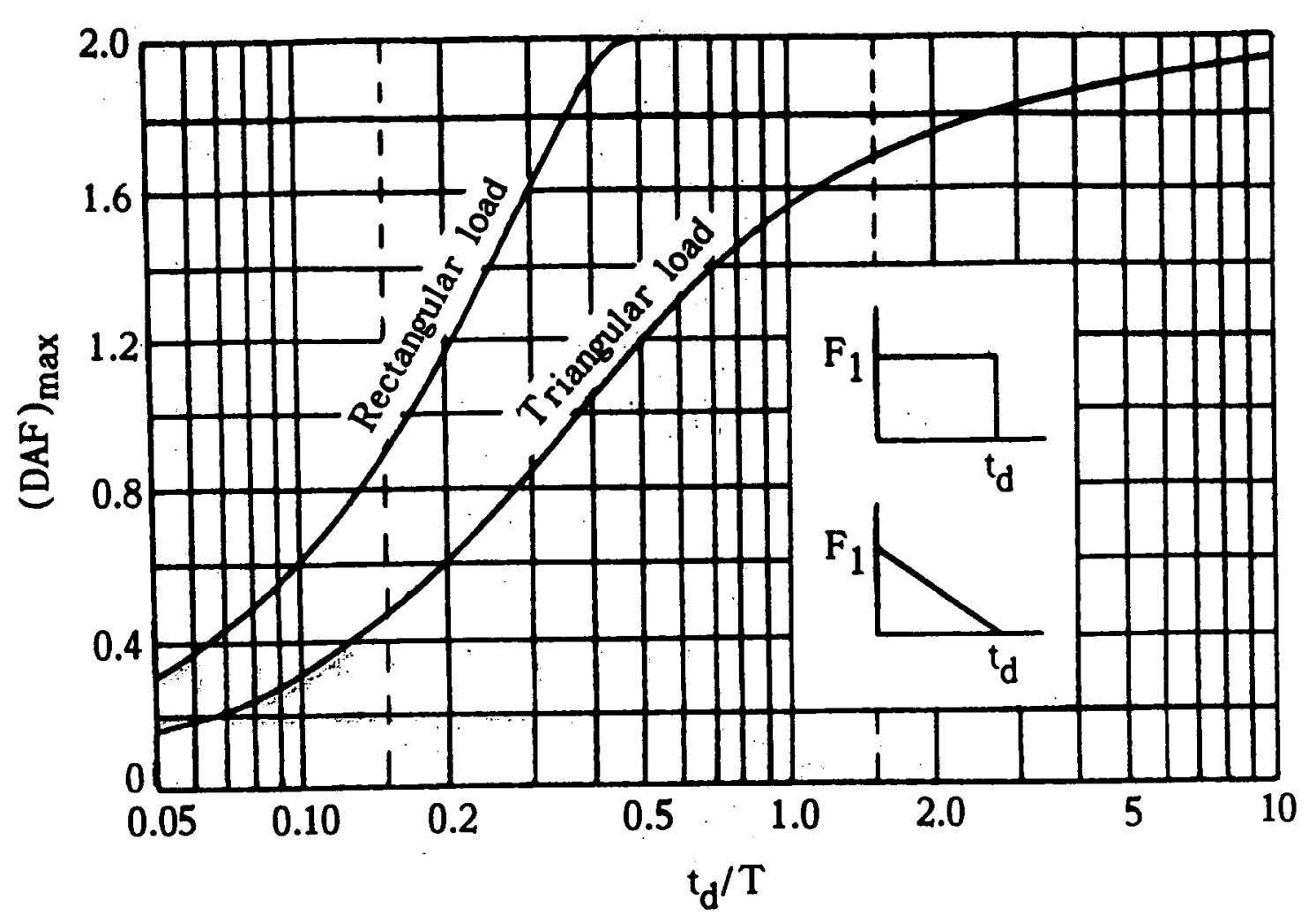

Fig. 2.2. Dynamic amplification factors for rectangular and trianguliar load shapes. (Ref. 5) 


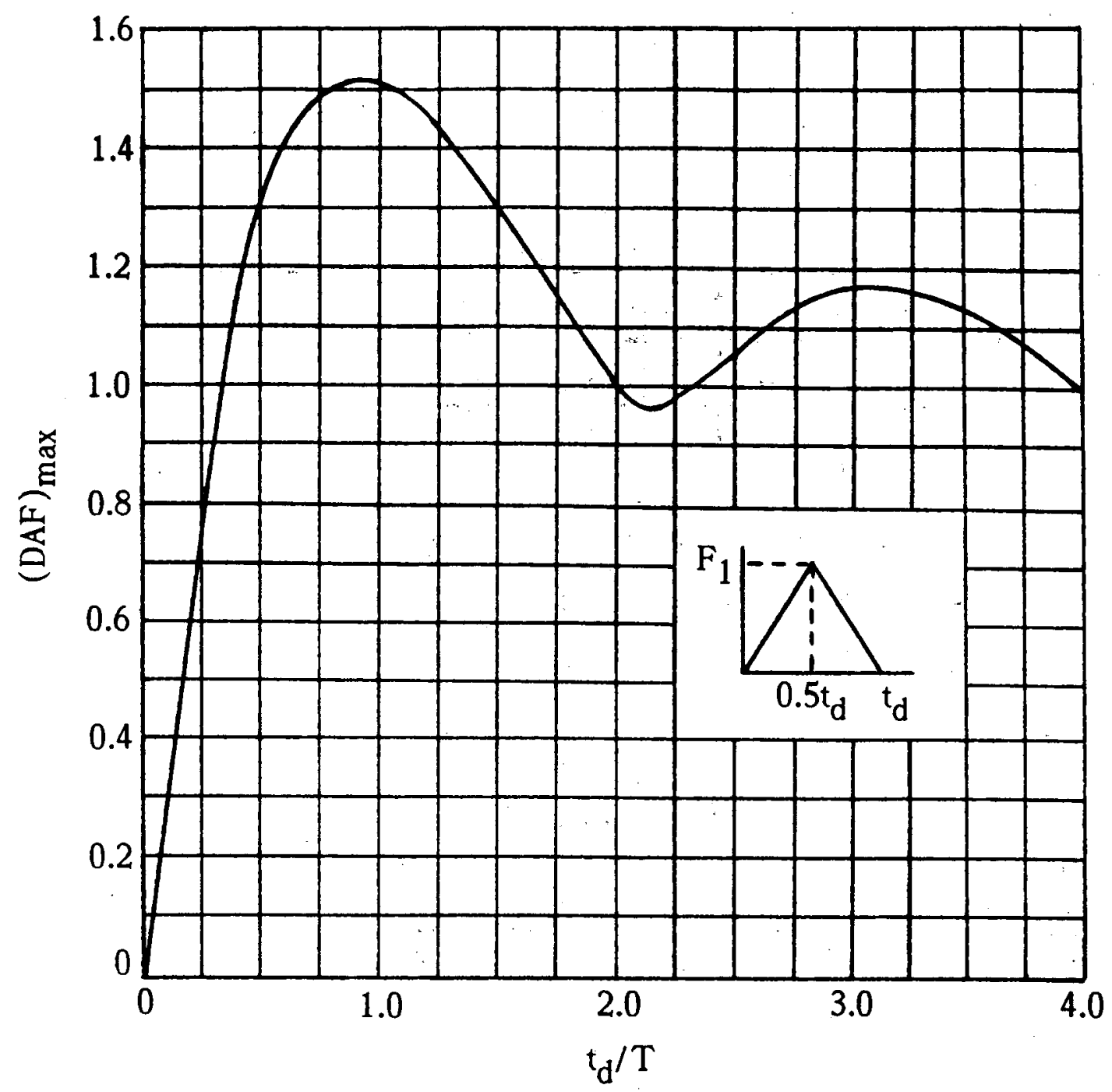

Fig. 2.3. Maximum dynamic amplification factor for a triangular 1oad. (Ref. 5) 
coaxial cylinders does not depend on the bonding assumption. The bending stiffness of coaxial cylinders is the sum of the individual cylinders whether they are bonded or not.

Other models have been proposed to account for various aspects of composite cylindrical casks employing lead shielding. One model (e.g. Ref. 7) attempts to account for the restraining effect of the outer shell on the radial motion of the lead which is modeled as an incompressible material. In this model, the outer shell has no resistance except for membrane stiffness in the circumferential direction. This model represents the opposite end of the spectrum from the perfectly bonded case where the primary resistance to axial deformation is provided by the axial stiffness of the steel shells surrounding the lead. This is due to the relatively soft Young's Modulus usually assigned to the lead at the expected strain levels. On the other hand, the radial strain of the lead will most likely be a major contributor to circumferential stress in the steel shells in the unbonded case. Models employing the bulk behavior of lead should provide conservative estimates of the circumferential stresses in the steel shells while underestimating longitudinal stresses in them.

\subsubsection{ASSUMPTIONS AND LIMITATIONS}

The most serious limitation of the lumped spring-mass models is that they can only model end-on impact. The only way to analyze oblique impact with a lumped parameter system is by use of combined axial-flexural elements such as beam elements. The standard beam element formulation doesn't include a determination of circumferential stresses directly. However, because beam elements are superior to the lumped springs, the remainder of this discussion will address on ly the beam formulation.

The difficulty in conducting an oblique impact analysis involves the combination of infinitesimal strains in the structure with large rigid-body rotations. The standard matrix analys is formulation does not account for the division of impact energy which is shared between strain energy in the beam elements and the kinetic energy associated with rigid-body motion. The governing equation of dynamic equilibrium for the conventional approach, which is not valid for large rotations, is as follows:

$$
M x+K\left(x-x_{0}\right)=P \text {. }
$$

For large rotations, the governing equation can be written as:

$$
\ddot{M x}+f=P \text {, }
$$

where,

$$
\begin{aligned}
& P=\text { external forces, and } \\
& f=\text { internal forces. }
\end{aligned}
$$


This formulation overcomes the limitation of the conventional approach. The system of equations that results can be solved by explicit time integration.

\subsubsection{MODELING CONSIDERATIONS}

The cask is modeled by a series of massless beam elements with lumped masses concentrated at the nodes. The axial stiffness, $A E$, and flexural stiffness, EI, are determined by assuming a composite section such as that shown in Fig. 2.4. For this example, the cask is divided into three regions: the top and bottom end caps, and the central shell. The properties of the end caps are found as follows:

$$
\begin{aligned}
A= & \pi R^{2} \\
I= & \pi R^{4} / 4 \\
E= & A \text { composite modulus, depending on the configuration } \\
& \text { of the end cap. }
\end{aligned}
$$

The composite beam properties become:

$$
\begin{aligned}
& A E=(A)(E), \text { and } \\
& E I=(E)(I) .
\end{aligned}
$$

In reality, the end caps are quite stiff compared to the shell region and can usually be treated as rigid masses and ignored in the stiffness formulation.

For the shell region, the properties can be calculated from the following:

Assume the shell is composed of 3 colinear cylinders, with radii to the surface of each shell described by

$r_{1}, r_{2}, r_{3}$ and $r_{4}$, and the material of each cylinder described by $\operatorname{modul} 1 E_{1}, E_{2}$, and $E_{3}$. Then,

$$
\begin{aligned}
& A_{1}=\pi\left(r_{2}{ }^{2}-r_{1}{ }^{2}\right), \\
& A_{2}=\pi\left(r_{3}{ }^{2}-r_{2}{ }^{2}\right), \\
& A_{3}=\pi\left(r_{4}{ }^{2}-r_{3}{ }^{2}\right), \\
& A E=A_{1}\left(E_{1}\right)+A_{2}\left(E_{2}\right)+A_{3}\left(E_{3}\right), \\
& I_{1}=\pi\left(r_{2}^{4}-r_{1}^{4}\right) / 4, \\
& I_{2}=\pi\left(r_{3}^{4}-r_{2}^{4}\right) / 4, \\
& I_{3}=\pi\left(r_{4}^{4}-r_{3}^{4}\right) / 4, \text { and } \\
& E I=E_{1}\left(I_{1}\right)+E_{2}\left(I_{2}\right)+E_{3}\left(I_{3}\right) .
\end{aligned}
$$

The total translational and rotational mass and length of each region are input individually. They are calculated as follows: 


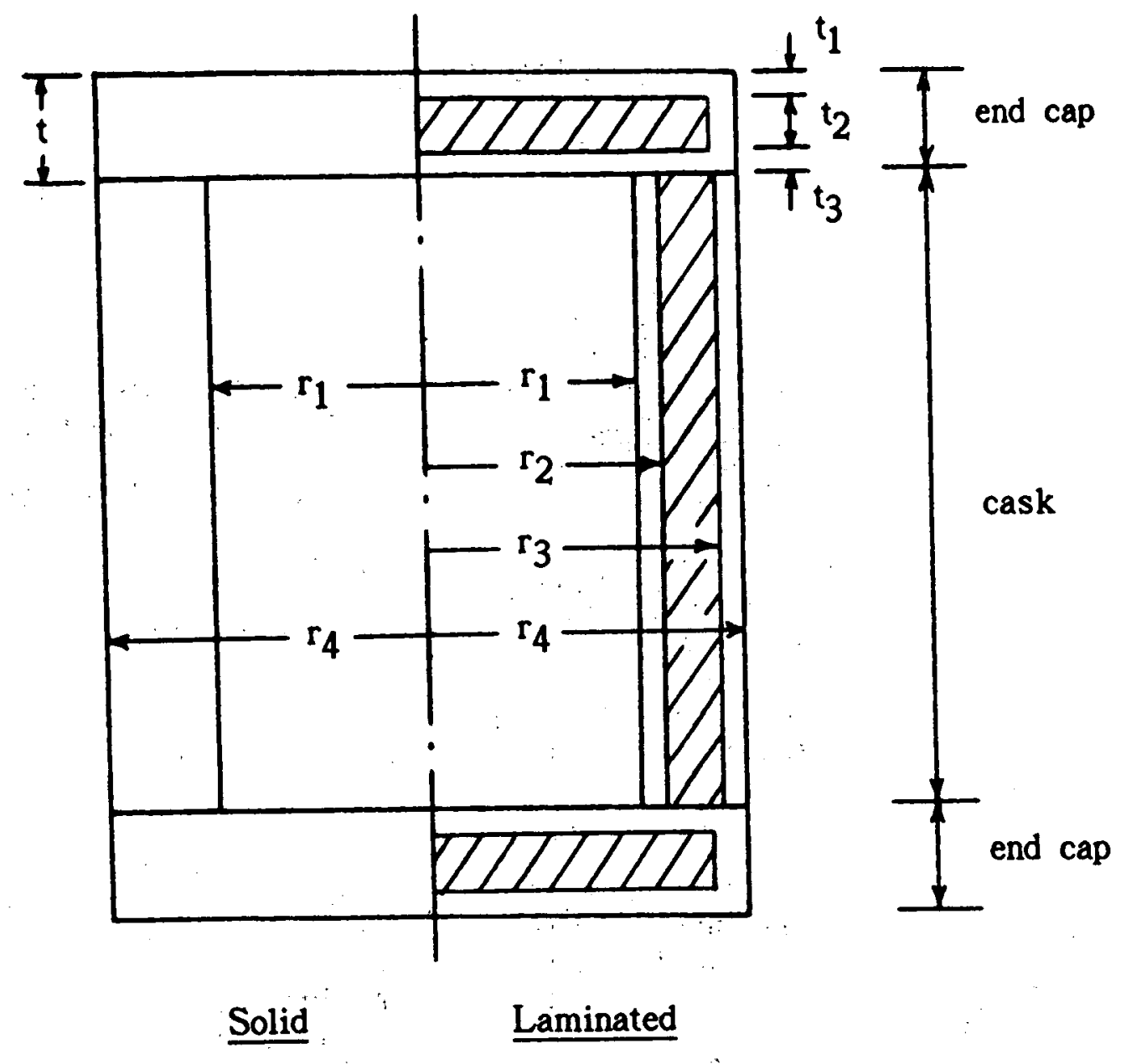

Fig. 2.4. Example cask model. 
Translational mass:

$$
\begin{aligned}
& \text { tmass }(i)=L_{i}\left[\rho_{1} A_{1}+\rho_{2} A_{2}+\rho_{3} A_{3}\right]+\text { contents } \\
& \text { where } \rho=\text { mass density of the appropriate she } 11 \\
& L_{i}=\text { length of element " } i "
\end{aligned}
$$

Rotational mass:

$\operatorname{rmass}(i)=L_{i}\left[\rho_{1}\left(I_{1}\right)+\rho_{2}\left(I_{2}\right)+\rho_{3}\left(I_{3}\right)\right]$

The total rigid-body rotational inertia has contributions from both the translational and rotational masses lumped at the nodes. Their relative contributions can be visualized by considering the rotation of a hollow circular cylinder about a transverse axis at one end. For a continuum element, the rotational moment of inertia is,

$$
r_{m}=m\left[\left(r_{1}^{2}+r_{2}^{2}\right) / 4+L^{2} / 3\right] \text {. }
$$

The first term is equivalent to (L)( $\rho$ )(I) as previously shown. This represents the rotational inertia induced by having mass located off the centerline. The second term is the rotational inertia of a slender rod, rotating about one end. The equivalent lumped-mass approximation for the second term is accounted for by the lumped translational mass located at a distance, $L$, from one end. This approximation, for a one-element model, is $\mathrm{mL}^{2} / 2$, which is conservative. As more elements are used to describe the model, the equivalent rotational inertia converges to that for the continuum. In summary, if a cask is long and narrow, the second term will predominate. If it is wide compared to its length, the first term will become more significant. Also, if the cask is wide compared to its length, shear deformation can become a significant contributor to overall cask response. The shear area can be calculated by multiplying the actual area by the shear factor appropriate for the shape of the cross section and Poisson's ratio of the material (Ref. 8).

Another element of a shipping cask which must be modeled is the impact limiters. Use of a lumped-parameter model limits the type of impact limiter to that which provides clearance in a lateral drop, i.e., the total package is a "dumbbe11" shape. The uniaxial models cannot predict the shell response of a cylinder impacting with a contact area along its entire length. However, it can adequately analyze the bending behavior of a cask that impacts only at its two ends. The limiter itself can be modeled as a spring. The equivalent spring can be described by a force-deflection relationship. This relationship can be determined either by test or analytically, and would consist of a piecewise-linear approximation. A different curve must be input for each angle of primary impact used in the analysis as well as that for lateral secondary impact. While this type of model is easily input, it does have one drawback. In a dynamic analysis, the force-deflection curve can be easily tracked during loading. However, the unloading behavior is more difficult to 
predict. It would be reasonable to assume that the unloading modulus would be equal to the initial loading modulus. However, when a force-deflection relationship is used instead of a stress-strain relationship, the effective area must be known in order to simulate a given modulus. Thus, an effective force-deflection slope must be assumed. An essentially rigid unloading slope as shown in Fig. 2.5 may provide a sufficiently accurate approximation.

Since lumped-parameter models are uniaxial, if the resultant force in an oblique impact acts off-center it must be accounted for explicitly. This can be done by specifying a moment arm at the impacting end. This moment arm should represent an approximation for the expected center of the impact "footprint". Since the crush area of the impact limiter will change with time, some judgment will be required to make a best estimate for the moment arm if a constant value is assumed. The effective moment arm is dependent on the stiffness of the impact limiter as shown in Fig. 2.6. For a rigid limiter, the moment arm would be a constant value for any non-vertical impact angle. However, the component of the impact force parallel to the cask axis, which causes moment at the impacting end, will decrease as the initial impact angle gets closer to horizontal. For a soft limiter, the moment arm will increase by some continuous function as the initial impact angle decreases from vertical. For a stiff limiter, the same general behavior should occur but with a more rapid increase in moment arm to the center of gravity case, denoted CG in Fig. 2.6. It is anticipated that the moment arm will then remain approximately constant from that drop angle down to horizontal. Actually, the CG case can only be easily determined for the rigid limiter case, when the drop angle, $\theta=\arctan (L \backslash d)$, where $L$ is the cask length and $d$ is the diameter of the limiter. For a non-rigid limiter, there may be many impact angles where no net overturning moment occurs since both the cask overturning moment and the moment arm of the reaction. increase with decreasing impact angle.

\subsubsection{EFFECTS OF UNBONDED LEAD}

In the discussions concerning a composite representation of a laminated cask, it has been assumed that the lead shielding was bonded to the steel shelis such that strain compatibility was conserved. If the lead is unbonded, it may experience slump under vertical load; however, it should not affect the beam bending response of the cask.

Presently, little is known about the behavior of lead shielding and its interaction with concentric steel shells during impact of a spent fuel shipping cask. The behavior of lead shielding under axial loading is a complex phenomenon which will be affected by the bonding mechanism with the steel shells. Work on this subject, expected to begin at Lawrence Livermore National Laboratory (LLNL) in the future, is beyond the scope of this report.

A postulated model to characterize leads slump as a result of unbonded lead may fit within a lumped parameter formulation. It is anticipated that the model would use an additional degree-of-freedom to characterize the slump behavior within the confining shells. The lead would most likely be modeled with a frictionless contact between the lead and the steel shells which would 


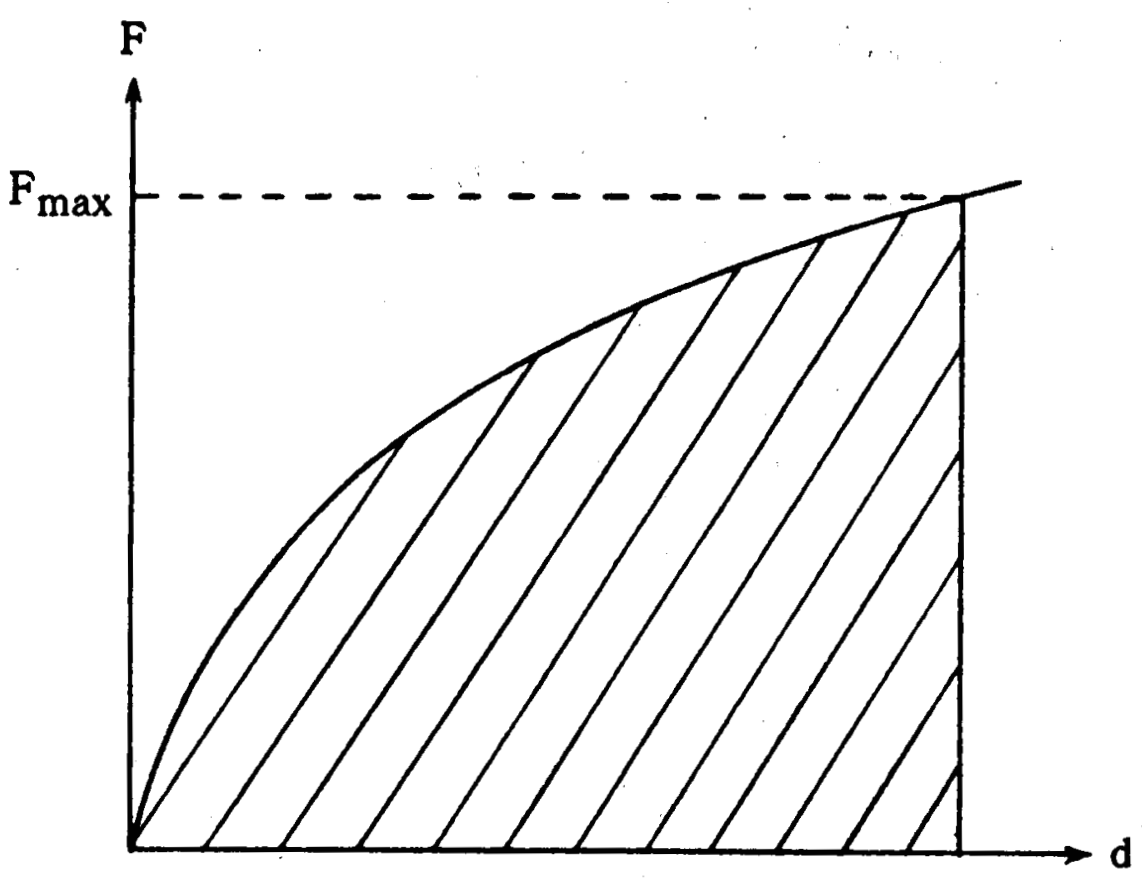

Fig. 2.5. Force-deflection curve of impact limiter. 

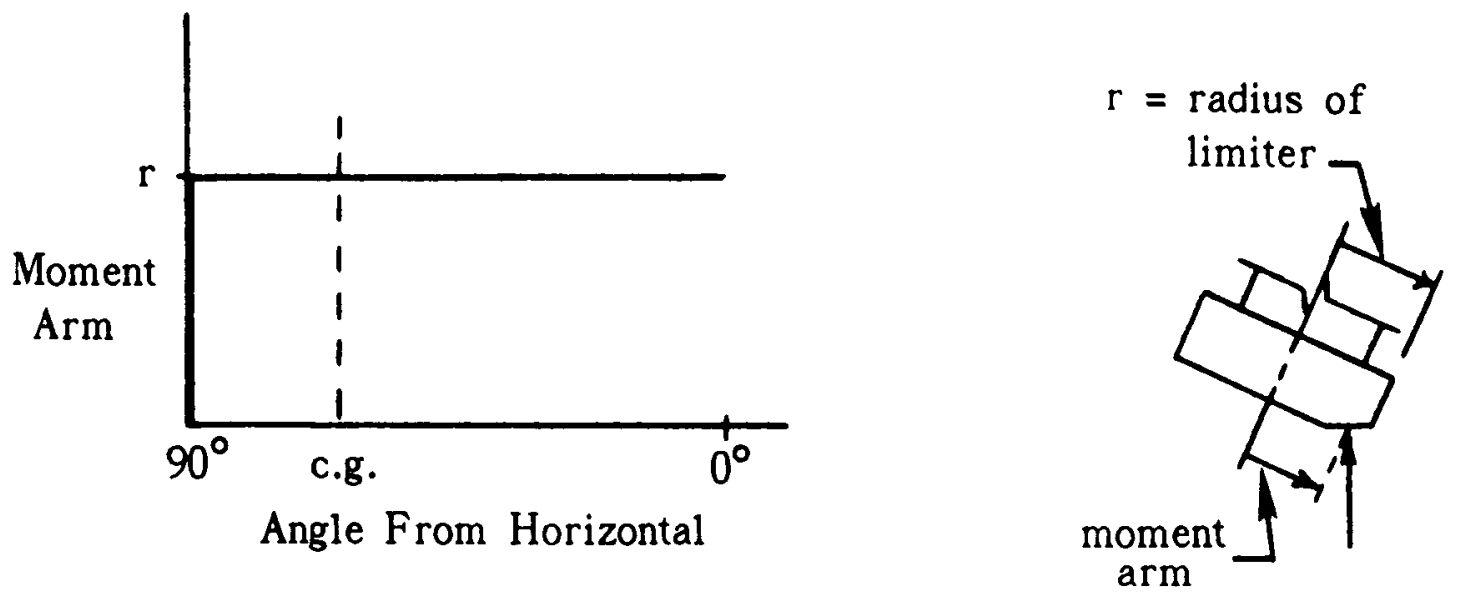

a. Rigid Limiter

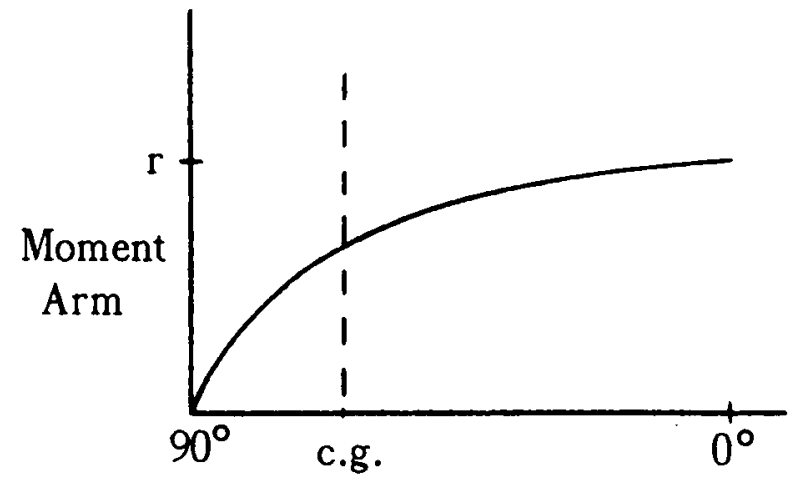

Angle From Horizontal

b. Soft Limiter

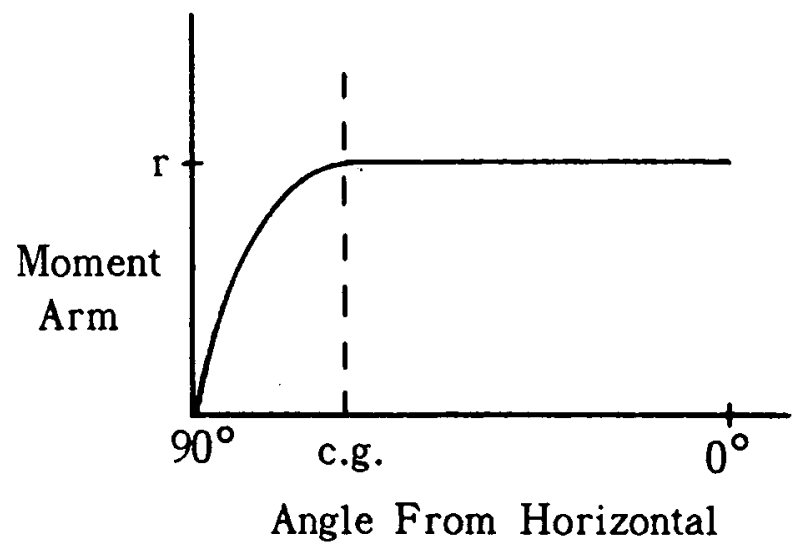

c. Stiff Limiter

Fig. 2.6. Postulated effective moment arms as a function of impact angle. 
produce a nearly hydrostatic condition. The friction between the lead and inner and outer shells is one parameter that should be investigated.

\subsection{QUASI-STATIC METHOD OF IMPACT AKALYSES}

\subsubsection{DESCRIPTION AND APPROACH}

In the shipping cask industry, a quasi-static impact analys is usually assumes the shipping containers to be rigid. The essence of the methodology lies in determining the maximum impact force, $F_{\max }$. The corresponding " $g$ load" due to impact is then

$$
g=F_{\max } / W
$$

where $W$ is the total weight of the cask.

Assuming the force-deflection curve of the impact limiter is known, the maximum impact force can be estimated by equating the area shaded in Fig. 2.5 to the change in kinetic energy $(K E)$ and potential energy (PE) during impact:

$$
\text { Shaded area }=\Delta(K E+P E) \text {. }
$$

In end-on, side and corner (c.g.) impacts, where the cask is stable after the initial impact, the distribution of forces in the rigid cask body is a simple matter, using the rules of statics, i.e, multiply the dead weight by a factor of ' $g$ '. In oblique impacts, where the cask is not stable after the initial impact, the force distribution is slightly more complicated. The following formula can be derived for the axial force, shear force and bending moment in terms of the impact force, $F$, which generally varies with time (see Fig. 2.7):

$$
\begin{aligned}
R & =\text { Axial force }=F \sin \theta(1-x / L), \\
V & =\text { Shear force }=F \cos \theta\left(3 x^{2}-4 L x+L^{2}\right) / L^{2}, \\
M_{b} & =\text { Bending moment }=F \cos \theta\left(x^{3}-2 L x^{2}+L^{2} x\right) / L^{2} .
\end{aligned}
$$

These equations were derived from the equations of motion of a slender rigid rod. (See Appendix A.) Note that the maximum bending moment occurs at a distance of $L / 3$ from the impact end.

The general case of oblique drops will be presented first, followed by end drops and corner drops which are considered as special cases of oblique drops. The side drop case is treated last as a separate case due to its unique boundary conditions. Throughout $\mathrm{Sec} .2 .2$, the cask is modelled as a slender rigid rod, and it is assumed that the cask has one impact limiter at each end. In addition, the kinetic energy is assumed to be $W$, where $h$ is the drop height. In other words, the additional deformation of the impact limiter has been ignored. 


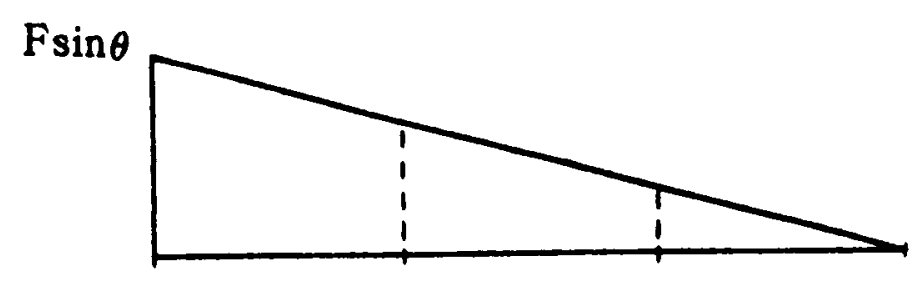

\section{Axial Force}
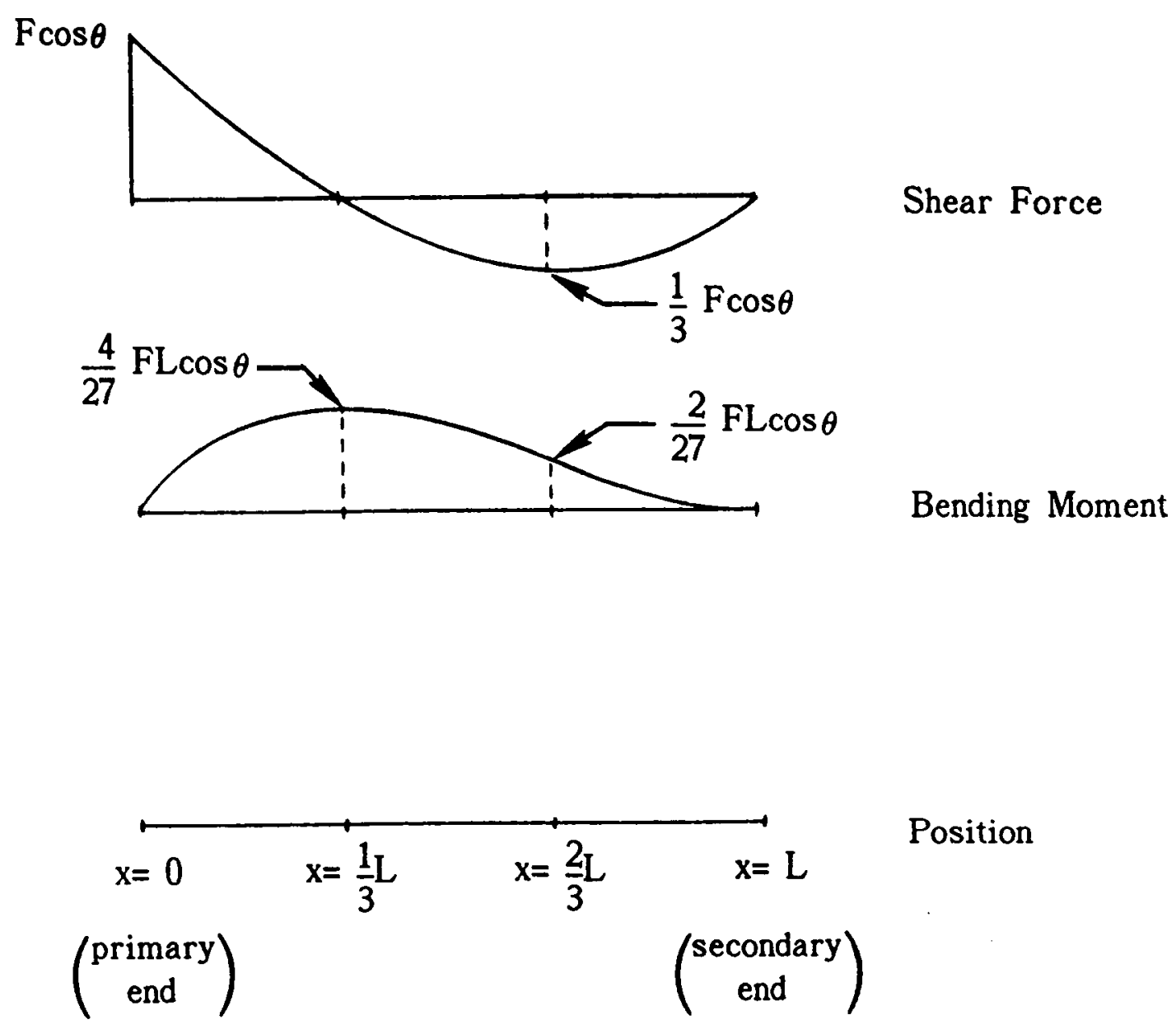

Position

Fig. 2.7. Internal force distribution in a primary oblique impact. 


\section{Oblique Drop}

The complexity in an oblique drop arises from the fact that the cask is not stable after the initial impact, which is accompanied by a rigid body rotation and followed by a secondary impact. In order to determine the impact forces during primary and secondary impacts, the following assumptions must be made that will lead to the energy distribution among the primary and secondary impacts:

(i) During primary impact, the cask is assumed to translate vertically. When the primary impact has stopped, the cask is assumed to begin rotating about the point of contact without sliding.

(ii) When the rotation hits the secondary end, it is assumed that the secondary impact will absorb the remaining kinetic and potential energy.

The limitations these assumptions put on quasi-static methods will be discussed in Sec. 2.2.3.

Primary Impact. Immediately before the primary impact, the initial conditions are:

$$
\begin{aligned}
& \dot{x}_{c \cdot g \cdot}=0, \\
& \dot{z}_{c \cdot g \cdot}=-v_{0}=-(2 g h)^{1 / 2} \text {, and } \\
& \dot{\theta}=0,
\end{aligned}
$$

where $g$ is the gravitational acceleration, $h$ is the drop height, and $\theta$ is the angle between the cask axis and the horizontal axis. The angular momentum about point 0 (see Fig. 2.8) before primary impact is, therefore,

$$
H_{0}=-M v_{0}(L / 2) \cos \theta
$$

where $M$ is the total mass of the cask, $v_{0}$ is the initial velocity, and $L$ is the length of the cask.

The motion after the primary impact is assumed to be a rigid body rotation about point 0 , so that the angular momentum about point 0 immediately after primary impact is

$$
H_{0}=I_{0} \dot{\theta}=\left[I_{c . g}+M(L / 2)^{2}\right] \dot{\theta}
$$

where $I_{0}$ is the mass moment of inertia about the point of contact, and I c.g. is the mass moment of inertia about the centroid of the cask. From the theorem of angular momentum, the rate the angular momentum changes during the 


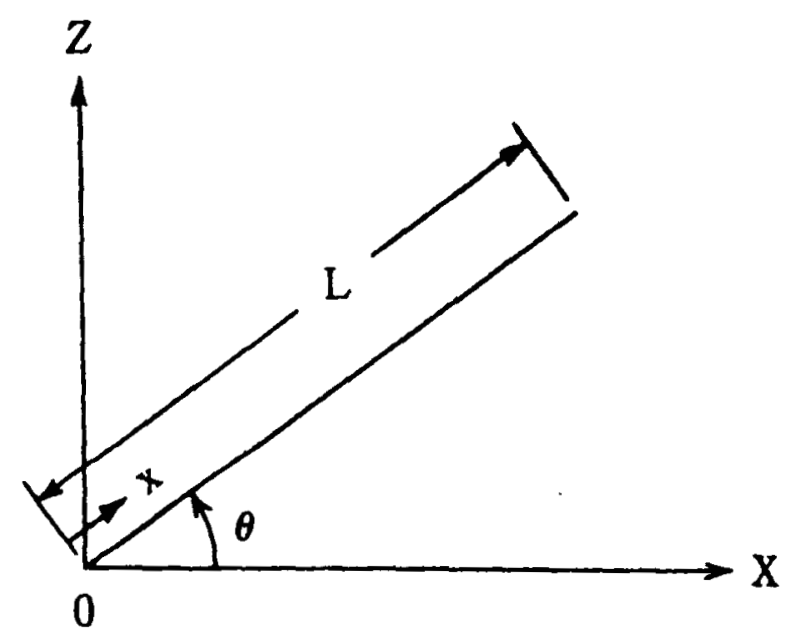

Fig. 2.8. Coordinate systems for oblique drops. 
primary impact is equal to the external moment about point 0 . Therefore,

$$
\begin{aligned}
& -W(L / 2) \cos \theta=\left\{\left[I_{c . g}+M(L / 2)^{2}\right] \dot{\theta}-\left[-M v_{0}(L / 2) \cos \theta\right]\right\} / \Delta t \text {, or } \\
& \left.\left[I_{c . g}+M(L / 2)^{2}\right] \dot{\theta}-\left[-M v_{0}(L / 2) \cos \theta\right]=-W(L / 2) \cos \theta \Delta t\right)
\end{aligned}
$$

where $\Delta t$ is the time during impact. Since the moment about point 0 is finite, and the time during impact is assumed to be infinitesimally small, the angular momentum must remain constant during the primary impact, i.e.

$$
\begin{aligned}
& {\left[I_{c . g .}+M(L / 2)^{2}\right] \dot{\theta}-\left[-M v_{0}(L / 2) \cos \theta\right]=0 \text {, or }} \\
& \dot{\theta}=-M v_{0}(L / 2) \cos \theta /\left[I_{c . g .}+M(L / 2)^{2}\right] .
\end{aligned}
$$

Next, the components of kinetic energy before primary impact, $K E_{1}$, and after primary impact $\mathrm{KE}_{2}$, are calculated as follows:

$$
\begin{aligned}
& K E_{1}=(1 / 2) \mathrm{Mv}_{0}^{2}=W h \\
& K E_{2}=(1 / 2) I_{0}(\dot{\theta})^{2}=(1 / 2)\left[I_{\text {c.g. }}+M(L / 2)^{2}\right](\dot{\theta})^{2} .
\end{aligned}
$$

Substituting $(2.2-6)$ into $(2.2-8)$, results in

$$
\begin{aligned}
K E_{2} & \left.=\{M[L / 2) \cos \theta]^{2} /\left[I_{c . g .}+M(L / 2)^{2}\right]\right\}(1 / 2) M v_{0}{ }^{2} \\
& =\left\{M[(L / 2) \cos \theta)^{2} /\left[I_{c . g .}+M(L / 2)^{2}\right]\right\} K E_{1} .
\end{aligned}
$$

From the theorem of conservation of energy, the work done in deforming the limiter is:

$$
\begin{aligned}
\text { Work } & =K E_{1}-K E_{2} \\
& =\left\{1-M[(L / 2) \cos \theta]^{2} /\left[I_{c . g .}+M(L / 2)^{2}\right]\right\} K E_{1} \\
& =\left\{1-M[(L / 2) \cos \theta]^{2} /\left[I_{c . g .}+M(L / 2)^{2}\right]\right\} W h .
\end{aligned}
$$

The maximum impact force can then be determined as discussed in Sec. 2.2.1, and the internal axial force, shear force and bending moment can be calculated according to equations $2.2-1$ to $2.2-3$.

Secondary Impact. At time $t_{3}$ (slapdown), the theorem of conservation of energy (see Fig. 2.9) can again be applied as follows:

$$
K E_{2}+P E_{2}=K E_{3}+P E_{3} \text {. }
$$

Since $\quad P E_{2}=0$, and $P E_{3}=-W(L / 2) \sin \theta$,

$$
K E_{3}=K E_{2}+W(L / 2) \sin \theta \text {. }
$$


Thus $\quad K E_{3}=\left\{M[(L / 2) \cos \theta]^{2} /\left[I_{c . g}+M(L / 2)^{2}\right]\right\} W h+W(L / 2) \sin \theta$.

Assuming all of $K E_{3}$ is absorbed by the secondary impact limiter, the maximum secondary impact force can be found as discussed in Sec. 2.2.1. Finally, the internal forces can be calculated using equations $2.2-1$ to $2.2-3$ (with $\theta=0$, and a change of origin (with $L-x$ replacing $x$ ). Then,

$$
\begin{aligned}
R & =\text { Axial force }=0 \\
V & =\text { Shear force }=F\left[3(L-x)^{2}-4 L(L-x)+L^{2}\right] / L^{2} \\
& =F x(3 x-2 L) / L^{2} \\
M_{b} & =\text { Bending moment }=F\left[(L-x)^{3}-2 L(L-x)^{2}+L^{2}(L-x)\right] / L^{2} \\
& =F x^{2}(L-x) / L^{2} .
\end{aligned}
$$

Equations 2.2-12 to 2.2-14 are plotted to show the internal force distribution at secondary impact in Fig. 2.10. Note that the maximum bending moment during secondary impact occurs at a distance of $\mathrm{L} / 3$ from the secondary impact end.

\section{End Drop}

In end-on impacts, the maximum impact force, $F_{\max }$, can be evaluated by equating the shaded area in Fig. 2.5 to the change in kinetic energy during the end-on impact, (which is equal to the potential energy before the cask is dropped), i.e.,

$$
\text { Shaded } \text { area }=\text { Wh. }
$$

After determining the maximum impact force, $F_{\max }$, the internal forces can be calculated as a special case of formulae 2.2-1 to 2.2-3. Thus, for end drops, the only non-zero internal force is the axial force:

$$
R=F(1-x / L) \text {. }
$$

This is a linear distribution as shown in Fig. 2.11 .

\section{C.G. Drop}

Strictly speaking, in a corner drop (see Fig. 2.12) where the cask is modeled as a slender rod, the cask is not stable after impact. Nonetheless, the internal forces due to impact can be calculated using equations 2.2-1 to 2.2-3 to yield:

$$
\begin{aligned}
R & =\text { Axial force }=F \sin \theta_{c \cdot g \cdot}(1-x / L) \\
V & =\text { Shear force }=F \cos \theta_{c \cdot g \cdot}\left(3 x^{2}-4 L x+L^{2}\right) / L^{2} \\
M_{b} & =\text { Bending moment }=F \cos \theta_{C \cdot g \cdot}\left(x^{3}-2 L x^{2}+L^{2} x\right) / L^{2}
\end{aligned}
$$




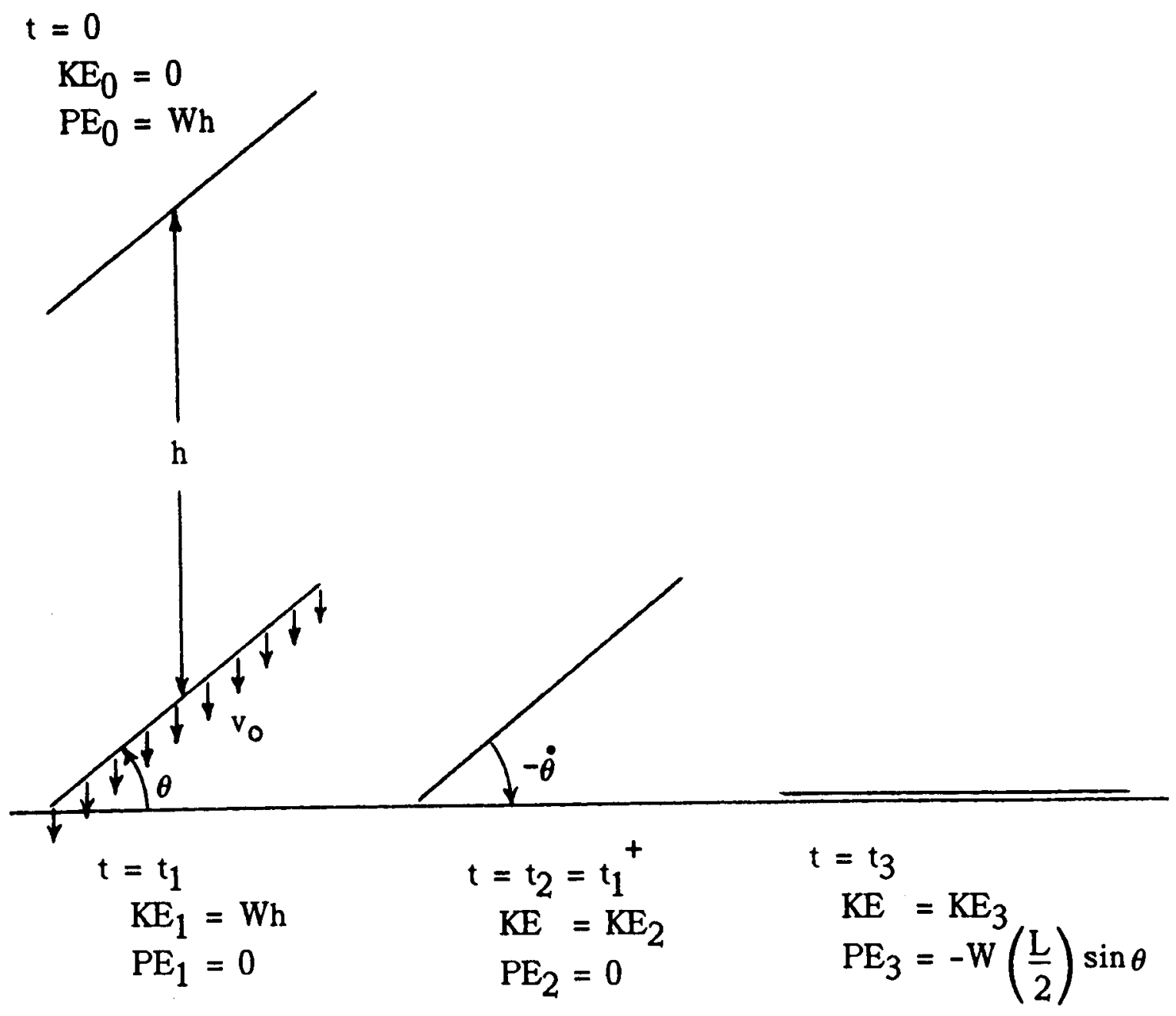

Fig. 2.9. Schematic of oblique impact. 

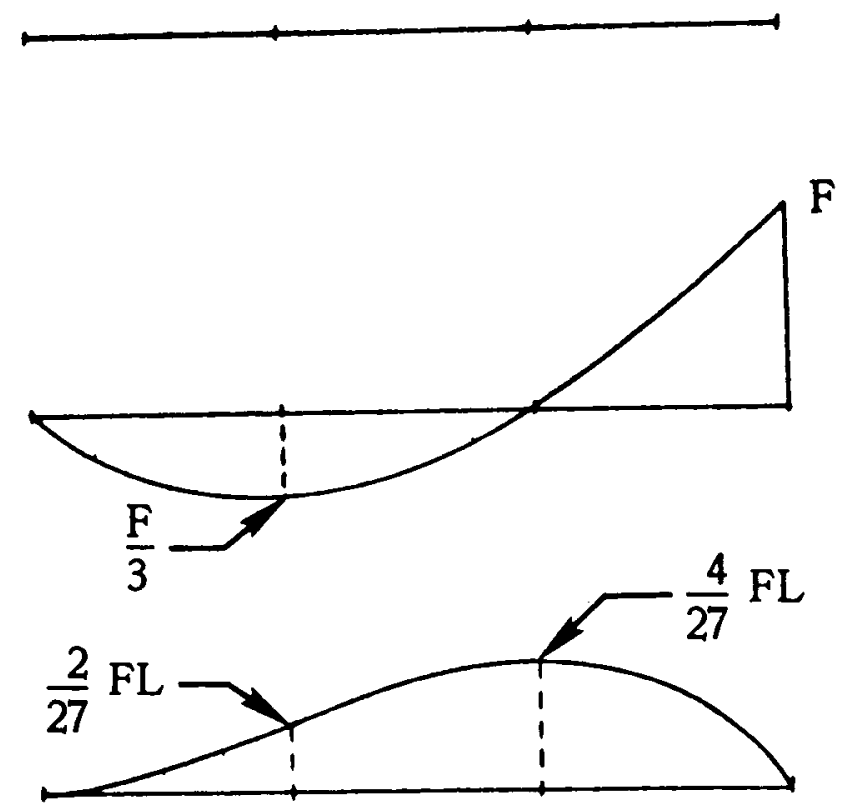

Bending Moment

Position

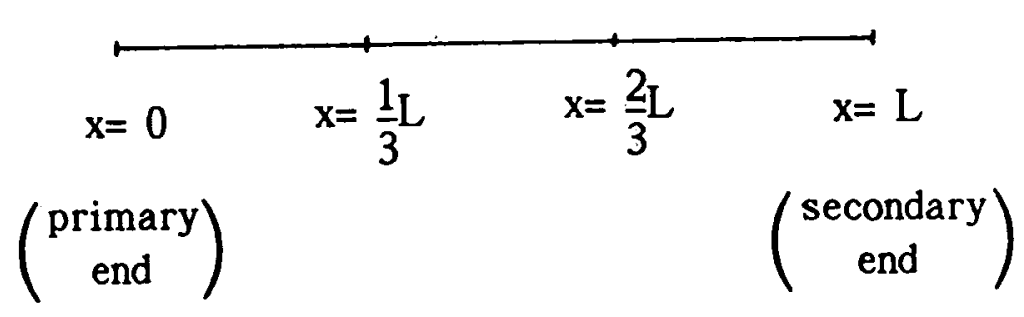

Fig. 2.10. Internal force distribution in a secondary oblique impact. 


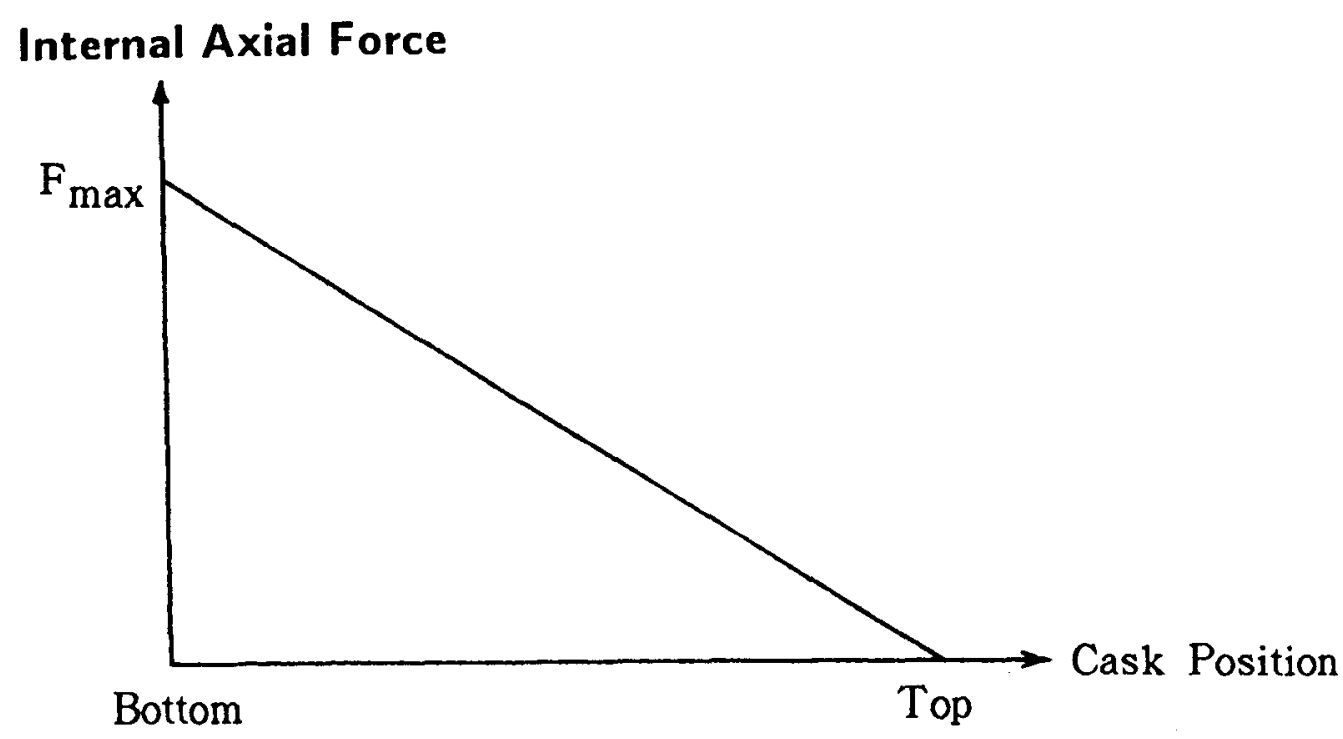

Fig. 2.11. Internal axial force in an end-on impact. 
where

$$
\begin{aligned}
{ }^{\theta_{C . g}} & =\arctan (L / d), \\
L & =\text { length of cask, and } \\
d & =\text { diameter of cask. }
\end{aligned}
$$

\section{Side Drop}

Assuming the top and bottom impact limiters have the same forcedeflection characteristics, the $F_{\max }$ in each impact limiter during a side drop can be estimated by equating the shaded area in Fig. 2.5 to $\mathrm{Wh} / 2$. Then the cask can be analyzed statically as a simply supported beam (see Fig. 2.13) with a uniform load of

$$
w=2 F_{\max } / L \text {. }
$$

The axial force in this case is zero, and the shear force and the bending moment can be calculated as:

$$
\begin{aligned}
V(x) & =F_{\text {max }}-w x, \text { and } \\
M_{b}(x) & =F_{\text {max }} x-w x^{2} / 2 .
\end{aligned}
$$

\subsubsection{APPLICATION OF QUASI-STATIC METHODS AND MODELING CONSIDERATIONS}

Quasi-static methods are used routinely in the industry for end-on, corner, or side impacts. After the $g$-load is found, $\left(g=F_{\max } / W\right)$, the internal force distribution can be calculated by multiplying the dead weight by a factor of " $g$ ". This is usually done quite easily by hand. For the more complicated cases of oblique impacts, computer codes can be developed using the methodology outlined here. In order to adequately depict the distribution of axial forces, shear forces and bending moments shown in Fig. 2.7, 2.10, 2.11 or 2.13, a minimum of several elements should be used in a quasi-static computer analysis.

LLNL, under contract to the U.S. Office of Nuclear Material Safety and Safeguards, is developing a computer code to perform oblique impact analyses for shipping containers. This code (IMPASC--IMPact Analysis of Shipping Containers) can do either dynamic or quasi-static analyses as described here. IMPASC is now operational on both the CRAY and IBM-PC computers. In the IBM-PC version, it is a part of a larger system of codes called SCANS (Shipping Cask Analysis System) which is being developed at LLNL and will eventually be able to handle other loading cases such as lead slump, thermal, and puncture. 


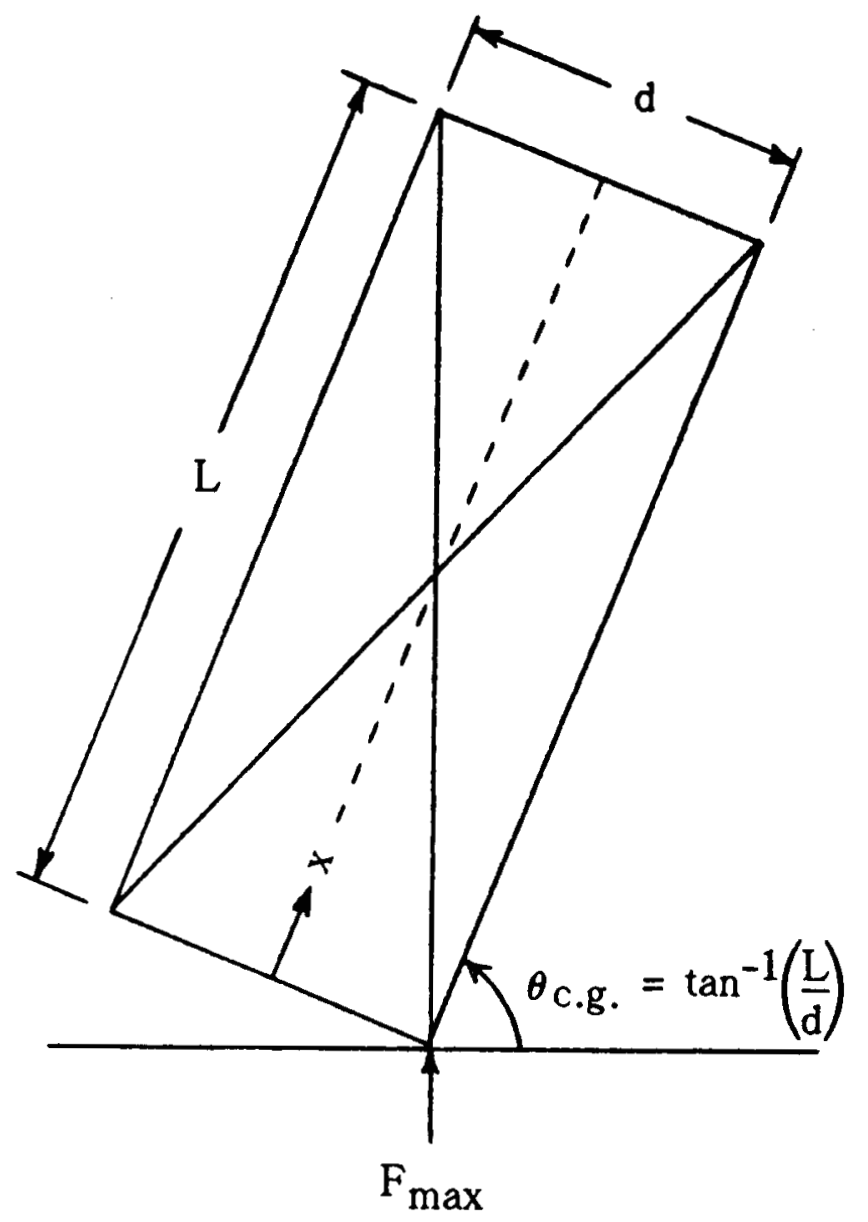

Fig. 2.12. Geometric parameters important to C. G. drop. 

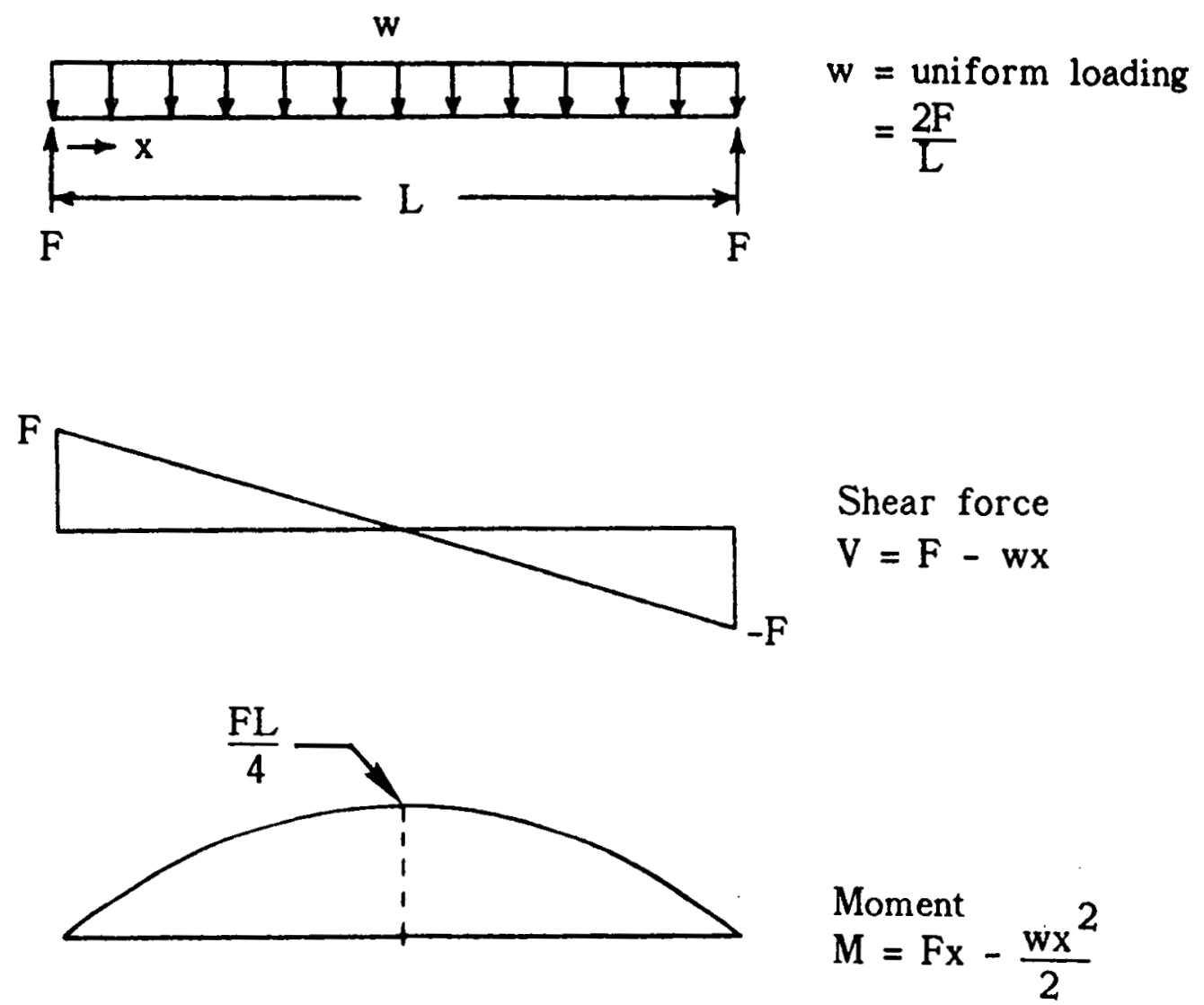

Fig. 2.13. Loading as a result of side impact. 


\subsubsection{LIMITATIONS OF QUASI-STATIC METHODS}

The common assumption of a rigid cask means that the flexibility of the falling body is ignored. The difference between the peak dynamic oscillatory response and that as predicted by quasi-static means is frequently referred to as the dynamic amplification factor (DAF). As discussed in Sec. 2.1, the magnitude of the DAF depends on the rate of loading as well as the ratio of the loading duration to the natural period of the cask. If no impact limiter is present, and the surface is rigid, the amplification factor is equal to 2.0 (see Fig. 2.14). The dynamic amplification factor will be reduced if the cask has a limiter. For example, if the loading by the limiter takes up to several times the natural period of the cask, the dynamic factor is only slightly larger than unity (see Figs. 2.3 ahd 2.15).

The two assumptions employed in the case of oblique impacts are quite arbitrary. The following comments can be made on these assumptions:

(i) During primary impact, the cask is assumed to translate vertically. When the primary impact has stopped, the cask is assumed to begin rotating about the primary impact end. In reality, rotation usually begins the moment the cask contacts the surface. In some cases, depending upon the limiter stiffness and the angle of the oblique drop, the primary end may even rebound. Thus, this assumption is reasonable only for a relatively soft limiter.

(ii) When the rotation causes the secondary end to hit, the secondary impact is assumed to absorb the remaining kinetic and potential energy; however, there may actually be more motion after the secondary impact.

The effects of the above two assumptions on the impact forces are unknown without further study; thus, the use of quasi-static methods for oblique impacts is not recommended. However, these methods can be used for the cases of end drops and side drops if a dynamic amplification factor is applied. In these two cases, the dynamic amplification factor can be approximated using Fig. 2.15 as follows:

Using Newton's Second Law,

$$
\begin{aligned}
F & =\Delta(M v) / \Delta t=M \Delta v / \Delta t, \text { or } \\
\Delta t & =M \Delta v / F .
\end{aligned}
$$

While it is recognized that $F$ varies with time, the impact duration $\left(t_{1}\right)$ can be approximated as:

$$
t_{1}=\Delta t=M v_{0} / F_{\max }
$$

where $M$ is the mass of the cask, $v_{0}$ the impact velocity, and $F_{\max }$ the maximum impact force.

The natural period of the cask can next be calculated as (Ref. 9): 


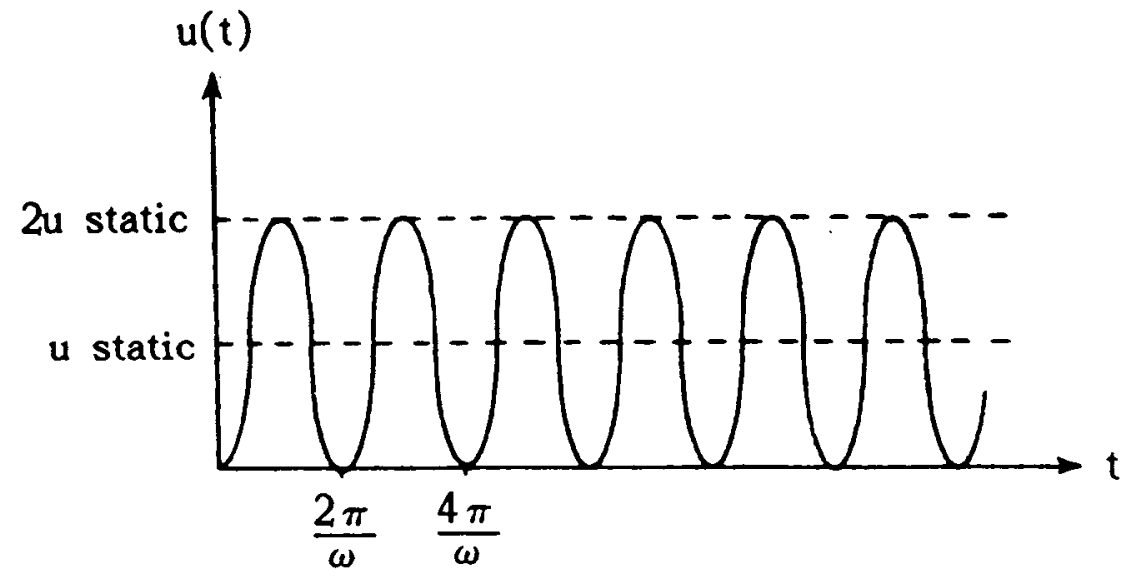

Fig. 2.14. Response to a suddenly applied step function (from Fig. 5.9-2 of Ref. 10). 


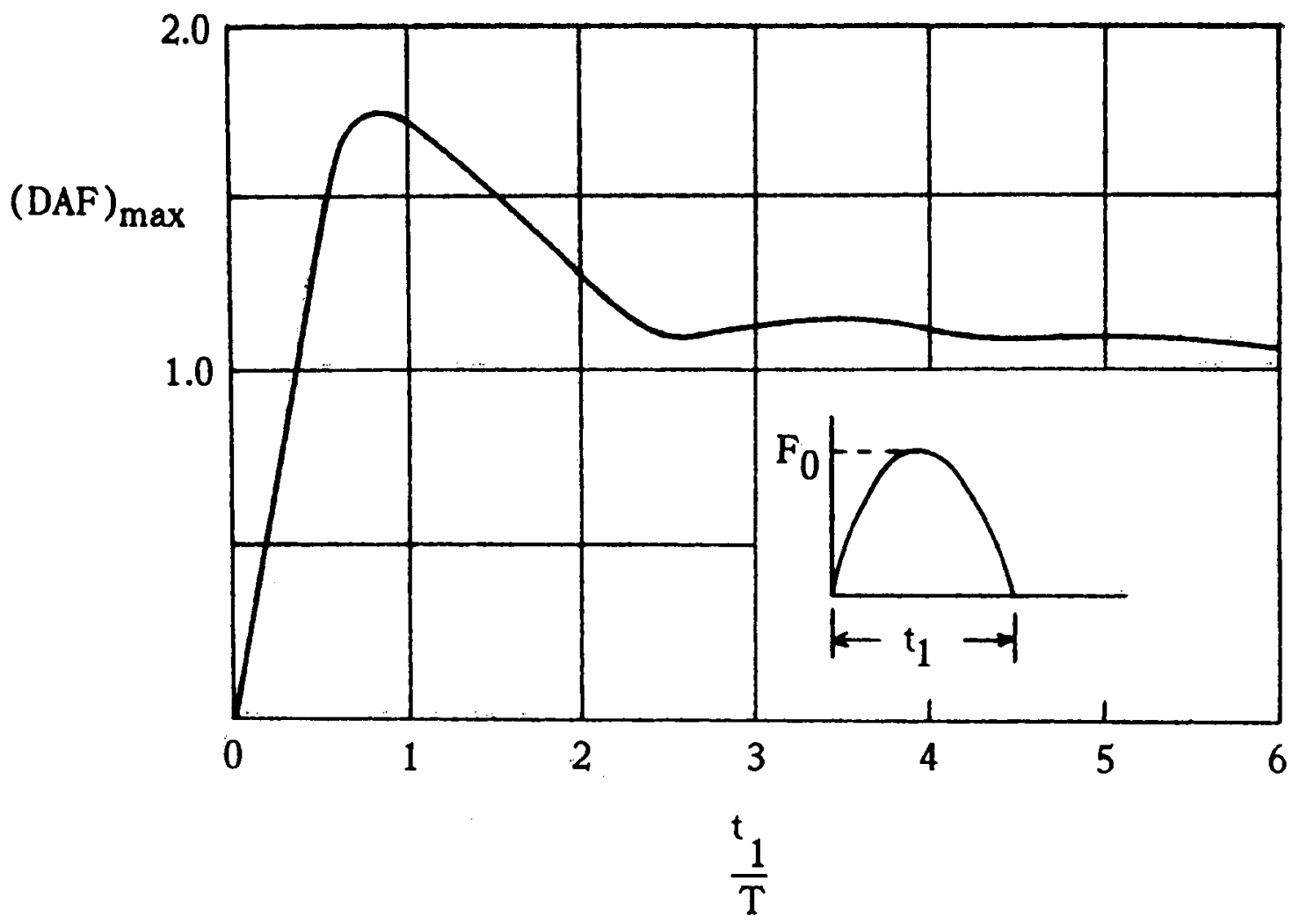

( $T$ = Natural period of structure $)$

Fig. 2.15. Amplification factor for a half-sine wave (from Fig. 4-5 of Ref. 11). 
$T=4 L / \sqrt{E / \rho}$ seconds (for end drop)

or

$$
T=1 / 1.57 \sqrt{\mathrm{EI} / \mathrm{ML}}{ }^{3} \text { seconds (for side drop) }
$$

From Eqs. 2.2-22 to 2.2-24, the ratio $t_{1} / T$ can be calculated from which the appropriate amplification factor can be determined using Fig. 2.15.

\subsection{DYNAMIC FINITE ELEMENT METHOD OF IMPACT ANALYSES}

\subsubsection{INTRODUCTION}

The finite element method (Refs. $12-14$ ) is widely used because of its ability to produce an accurate solution to problems with difficult and yet realistic boundary conditions. Since the dynamic equilibrium of a flexible structure is solved directly, it is not necessary to use a dynamic amplification factor in the dynamic finite element method. The use of onedimensional bar or two-dimensional plane-strain elements in the impact analyses of shipping containers obviously involves many simplifying assumptions. Even if those assumptions can yield qualitatively correct approximations, the detailed picture of stress distribution, as would be obtained by a three-dimensional analysis, will be lost. To obtain the truest picture of the response of complex systems such as shipping casks undergoing an oblique impact, analyses should be solved as three-dimensional problems. In such analyses, the stresses in the bolts, seals, closures, as well as in the containment walls, can be directly obtained. This eliminates the need for further stress recovery procedures which are sometimes necessary in onedimensional and two-dimensional analyses. With advancements in efficient software and super-computers, three-dimensional dynamic finite element analyses can be used to analyze the impact problems of shipping containers. Although the costs in three-dimensional analyses are much higher than onedimensional or two-dimensional analyses, it is much cheaper to conduct an analysis than to run a full-scale experiment.

A good review of the finite element method is provided in Refs. 15 and 16. In this section, selection and efficient application of the finite element method to impact analyses of shipping containers will be discussed.

\subsubsection{ANALYSIS AND MODELING CONSIDERATIONS}

\section{Classification and selection of finite element methods}

A finite element method can be formulated in three ways. When displacements are the independent variables, the methodology is called a displacement method. When forces (or stresses) are the independent variables, it is called a force method. Hybrid methods treat both displacements and stresses as independent variables (see Ref. 17). Existing finite element computer codes use almost exclusively the displacement method, possibly due to 
its straightforwardness in formulation. These discussions will assume the use of a displacement method finite-element program.

In a displacement method, the displacement variation within an element is assumed in terms of the nodal displacements. Thus, strains (through straindisplacement equations) and stresses (through constitutive laws) in the element can be expressed in terms of the nodal displacements. The equations of motion (in terms of stresses) then become a set of ordinary differential equations of second order in the time domain. This system of equations can be solved by either the direct integration technique or the mode superposition technique.

In the mode superposition technique, the eigenvectors are used to decouple the original nodal displacements in a transformed coordinates system. The decoupled equations are then solved and transformed back to yield the nodal displacements. If the number of modes required to give a good approximation to the equations of motion are known, the mode superposition technique can be quite effective, because the higher modes can then be ignored. In general, the number of modes depends on the type of loading as well as the details involved in the finite element model. If a beam-type element is used and the local stresses are to be recovered through formulae or other more detailed analyses, four or five modes may be sufficient. On the other hand, if a three-dimensional model detailing the bolts, closures and seals is used, up to fifty modes may be required. In any case, a postanalysis can be made to check the sufficiency of the chosen modes by performing a Fourier transform on the force-time curve of the impact force.

In the direct integration technique, which is available in more computer programs than the mode superposition technique, the equations of motion are solved directly in the original coordinate system. These direct integration techniques can further be classified into implicit and explicit categories. In implicit methods, (for example, Houbolt, Wilson, and Newmark methods) the displacements at time, $t+\Delta t$, are derived by solving the equations of motion at time, $t+\Delta t$. In explicit methods, (for example, the central difference method) the displacements at time, $t+\Delta t$, are derived by solving the equations of motion at time, $t$. The biggest advantage of implicit methods is that the implicit solution algorithms are unconditionally stable. However, if the time steps are too large, truncation errors will accumulate and propagate. This will be further commented on in the discussion on time step size and in Sec. 2.3.3. Explicit solution algorithms, on the other hand, are only conditionally stable, and explicit computer programs will typically choose a step size small enough to ensure stability. This seemingly serious disadvantage is offset by the feature that explicit algorithms do not require matrix inversions when a lumped mass approach is used and damping is ignored. In general, it can be stated that for high velocity (greater than $1500 \mathrm{ft} / \mathrm{s}$ ) impacts, explicit integration methods are more appropriate. In low velocity impacts (which include the regulatory 30-ft drop with impact velocity of only about $44 \mathrm{ft} / \mathrm{s}$ ), either explicit or implicit integration schemes can yield accurate results. 


\section{Selection of mesh size}

Shipley, Leistner and Jones (Ref. 18) observed that finite element models behave like low-pass filters having definite passing bands and cutoff frequencies and that the cutoff frequencies depend on the finite element mesh. In other words, waves with frequencies above the cutoff frequency will be filtered. Determining the highest desired frequency is similar to determining the number of modes to be included in a mode superposition analysis. This was discussed in the previous section. In general, cutoff frequency selection depends on the type of loading as well as the details involved in the finite element model. The following two examples illustrate the kind of formulae that can be used:

(a) For a uniform bar vibrating along its longitudinal axis with a fixedfree boundary condition, (Ref. 9), the lowest three natural frequencies (radians per second) can be calculated from the following:

$$
\omega_{n}=K_{n}(E A / M L)^{1 / 2}
$$

where

$$
\begin{aligned}
& E=\text { Young's modulus } \\
& A=\text { area of bar } \\
& M=\text { mass of bar } \\
& L=\text { length of bar }
\end{aligned}
$$
and

$$
\begin{aligned}
& k_{1}=1.57 \\
& k_{2}=4.71 \\
& k_{3}=7.85
\end{aligned}
$$

The above example represents the frequencies needed to capture the first three axial vibration modes as in a cask end-drop.

(b) For a uniform beam vibrating with a hinged-free boundary condition, the lowest three natural frequencies (radians per second) can be calculated from the following (Ref. 9):

$$
\omega_{n}=K_{n}\left(E I / M L^{3}\right)^{1 / 2}
$$

where

$$
\text { and } \begin{aligned}
I & =\text { moment of inertia of cross-section of beam } \\
K_{1} & =15.4 \\
K_{2} & =50.0 \\
K_{3} & =104.0
\end{aligned}
$$


This example represents the frequencies needed to capture the first three lateral vibration modes as in a cask side or oblique drop.

For end-drops, axial vibration would be the controlling consideration, whereas for side-drops, lateral vibration would be the governing factor. For oblique drops, both axial and lateral vibrations should be taken into consideration. Knowing the highest frequency, wax, the smallest wavelength can be calculated as follows:

$$
\lambda_{\min }=c / \omega_{\max }
$$

where

$$
\begin{aligned}
c= & \text { sound speed }=(E / \rho)^{1 / 2} \text { which is exact in 1-d } \\
& \text { and approximate in } 2-d \text { and } 3-d \text { problems, and } \\
\rho= & \text { mass density. }
\end{aligned}
$$

The maximum finite element mesh size, should be limited to less than oneeighth of the wavelength of the highest frequency (Ref.19).

\section{Time Step Size and Duration of Analysis}

In explicit methods, the integration is only conditionally stable and explicit programs typically will internaliy calculate the size of the time step required for stability. In implicit methods, however, the user must specify the size of the time step. There is no general rule available for this time step size. From the authors' experience, the following formula is recommended:

$$
\Delta t=10 \Delta x /\left[(E / \rho)^{1 / 2}\right],
$$

where $\Delta x$ is the smallest dimension used in defining the element mesh; $E$ is Young's modulus; and $\rho$ is the mass density. In other words, a time step an order of magnitude larger than those in explicit methods may be used.

The duration of time-history integration for impact analyses of shipping casks depends on the stiffness of its limiters. Usually, 0.15 second will be sufficient for most end, c.g., side, and shallow oblique drops. For oblique drops close to the vertical (for example, 80 degrees from the horizontal) capturing secondary impact may require integration up to a couple of seconds.

\section{Example of a Three-dimensional Finite Element Impact Analys is}

A good example of a three-dimensional finite element impact analysis can be found in Ref. 20, which used DYNA3D (Ref. 21) to model a center-of-gravity over corner drop. This example (see Fig. 2.16) demonstrates design features such as bolted closures, seals and shear rings. These areas are expected to be more highly stressed than other areas and thus have a finer mesh representation in the finite element model. 


\subsubsection{DESIRABLE FEATURES OF COMPUTER PROGRAMS}

Analyses of cask impact problems present some unique challenges for available analytical tools. Computer programs to solve these problems should have the following features:

(a) Oblique impacts of shipping containers involve very large rigid body motions, even though the deformation may be very small. Therefore, it is important to choose a computer program that has either a large strain formulation, or a corotational (rigid-convected) coordinates system (Ref. 22).

(b) Oblique impacts are basically three-dimensional problems. Since three-dimensional dynamic finite element analyses are both expensive and time consuming, a restart capability should be included.

(c) To analyze a shipping container dropped onto an essentially rigid surface, a rigid wall or a stonewall boundary condition should be specified.

(d) When the impact limiter is very soft, it may distort to a state such that a negative mass is calculated. Therefore, a rezoning capability is desirable. If rezoning occurs frequently, care should be taken interpreting numerical results. Frequent rezoning has the features of Eulerian codes, i.e. allowing materials to flow through the grids."

(e) Since many shipping containers have quite soft impact limiters, the material library should contain a crushable foam.

(f) In order to characterize lead slump the computer code should have a slideline capability.

(g) The code should allow plotting the sumation of kinetic, potential, and internal energy terms in order to assure that total energy is conserved.

(h) If an implicit computer program is chosen to do the impact analyses, truncation errors may accumulate and:propagate. To alleviate this concern, an implicit program should allow the options to iterate on equilibrium and reform the stiffness matrix.

(i) Dynamic finite element analyses usually produce an enormous amount of results. Therefore, a good postprocessor that will arrange the results in graphical form is needed.

\subsubsection{LIMITATIONS AND CLOSURE}

With improvements in software and hardware efficiencies, the costs incurred in a finite element analysis can be easily justified. In the finite element impact analyses the authors are aware of, only end drops, side drops, 


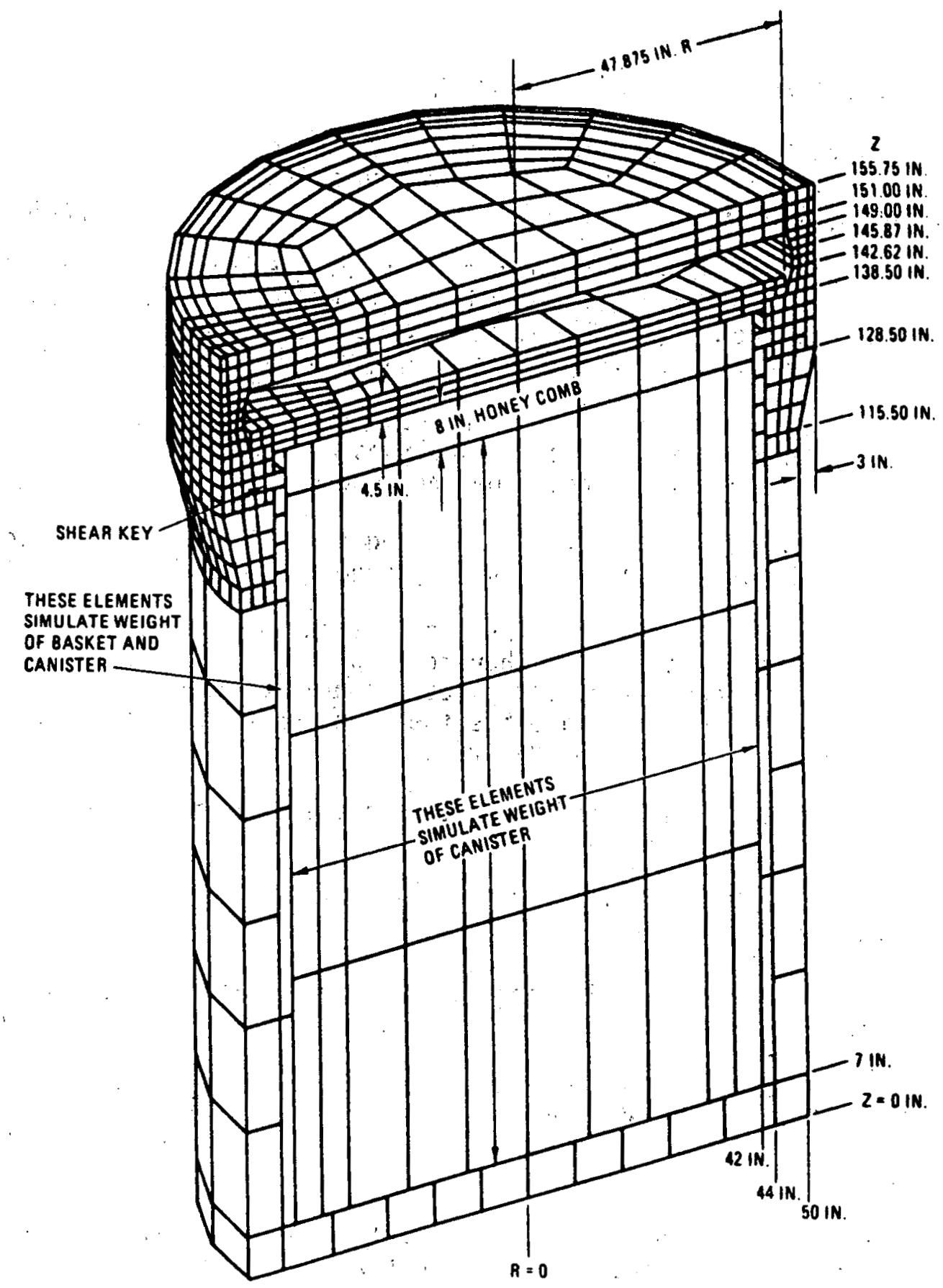

Fig. 2.16. Example of three dimensional finite element'mesh (from Ref. 20). 
or center-of-gravity over corner drops are considered. (In the shipping cask industry, these three orientations are sometimes assumed to encompass the worst-case conditions.) Unless this can be proven, oblique impacts should be included in determining the critical orientation of impact analyses.

To diminish some of the concerns raised above, LLNL is developing a system of computer programs called SCANS (Shipping Cask Analysis System). SCANS currentiy can perform impact and thermal analyses. (Future extensions to puncture and buckling are being investigated.) The impact portion of SCANS is called IMPASC (IMPact Analys is of Shipping Containers), which is an explicit, finite-element computer program using beam elements (in a twodimensional plane) with a corotational (rigid-convected) coordinate system. With this formulation, problems which combine small deformations with large rigid-body motions can be analyzed. IMPASC does not currently include the capability to analyze large deformations nor nonlinear cask material properties. It is the only computer program, we are aware of, that has been used to perform dynamic analyses of a cask falling at an oblique angle. It captures the response at al1 three stages, primary impact, the subsequent large, essentially rigid-body rotation, and, finally, secondary impact. 


\subsection{STRESS EVALUATION}

\subsection{DESIGN CRITERIA AND STRESS CATEGORIES}

Design criteria are specified in Regulatory Guide 7.6 for the structural analys is of shipping cask containment vessels. The criteria are adopted from the design requirements for nuclear power plant components contained in Section III, NB3200 of the ASME Code (Ref. 23).

The basic philosophy of the ASME Code was founded upon elastic models of structural and material behavior for ductile shell structures. The maximum shear stress theory of failure is used as a basis for allowable stresses. A stress intensity defined as twice the maximum shear stress is used as the measure of stress. To preclude failure, the stress intensity is required to be less than or equal to the stress intensity limit specified for a given or combined loading condition. The stress intensity limit depends upon either a design intensity value, $S_{m}$, or a tensile strength value, $S_{u}$, for each material of construction at the specified temperature. Failure modes addressed by the stress acceptance criteria are gross rupture, progressive deformation and fatigue. Reference 24 provides the basic code philosophy for the establishment of stress acceptance criteria for the specified categories of stress intensity.

General guidance and stress definitions are provided in NB3200 of the ASME Code for classification of stresses in vessels. The stress classifications are:

$$
\begin{aligned}
& P_{m} \text { - General Primary Membrane } \\
& P_{L}-\text { Local Primary Membrane } \\
& P_{b}-\text { Primary Bending } \\
& Q \text { - Secondary } \\
& F-\text { Peak }
\end{aligned}
$$

The stress classification depends on whether the loading event is load controlled or deformation controlled. A stress resulting from a load controlled event, such as impact, may be in any of the above categories, but a stress resulting from a deformation controlled event may only be secondary or peak. For instance, internal pressure results in a load controlled condition. The general membrane stress that results from that pressure is primary in that deformation of the vessel will not relieve the general membrane load. At the junction of the vessel head to the cylindrical shell, there is both membrane and bending stress. In curved shells, the primary load resistance path is membrane loading. Bending caused by incompatible rotations of adjacent shell segments results in secondary stress in that a small amount of inelastic deformation satisfies the rotation incompatibility and relieves the applied moment in the joint. Peak stress may result at a local discontinuity (notch). Any local yielding relieves the localized loading without altering the general equilibrium of the structure. 
In Fig. 3.1, a procedure is outlined for identifying and combining loads, classifying stresses, and comparing the stress results with the acceptance criteria specified in Regulatory Guide 7.6. First of al1, individual loading conditions are identified for normal and accident conditions. Individual loading conditions and initial environmental conditions are specified in Regulatory Guide 7.8. Some of the load conditions specified have both positive and negative directions of loading depending on the environmental conditions. As such, each specified load combination may result in several sets of stress resultants. Stresses due to fabrication processes such as lead pouring and shrink fitting are assessed for inclusion in any detailed analysis. Loads due to cask operations such as internal pressure and temperature gradients may have to be included in the analysis. Cursory analyses may be performed to determine which loads should be calculated in detail and combined with the impact loads.

\subsection{STRESS RECOVERY FROM SIMPLIFIED MODELS}

Simplified models are those in which uniaxial elements are used to represent the cask. Examples include those used in the quasi-static method and the lumped parameter method. In these methods, the results of the analys is are in term of moments, shears, and axial forces in the elements. These global values must then be converted into stresses in order to evaluate the performance of the material. The method used to recover stresses is dependent on the configuration of the cask as illustrated in Fig. 3.2. For either solid or laminated casks, the primary membrane stress is composed of the axial force at a section divided by the cross-sectional area plus the average bending stress through the section thickness. This calculation is straightforward for the solid cask, i.e., P/A $\pm M c_{a v g} / I$. "However, for the laminated cask, the portion of the section forces resisted by each material must be weighted by its relative stiffness as determined by its modulus. Assuming plane sections remain plane, the axial contribution for material " $i$ " is given by $P E_{j} / A E$, and the bending contribution is given by $M E_{j} C_{j} / E I$, where $A E$ and $E I$ are composite section properties as described in Sec. 2.1.3.

The primary membrane stress accounts for only the average axial stress across the section. The primary bending stress accounts for the variation in stress across the cross section but has a higher allowable value associated with it. Normally, the ASME Code (Ref. 23) compares stress intensities against allowables. For a beam model, the stresses at or near the extreme fiber are considered to be uniaxial since the shear stress is at or near zero at this location. Thus, the uniaxial stresses are principal stresses and also are stress intensities. This would not be the case, in general, if lateral pressures due to lead slump were to occur during impact and, in fact, will not be the case when other loads are superposed in a load combination. However, for the purpose of evaluating the important features of impact stresses alone, without lead slump, a uniaxial stress comparison is valid at the extreme fiber.

The solid cask exhibits the greater variation of stress through the thickness as shown by $\mathrm{Pb}_{b}$. However, it is relatively small for the example 
$R G 7.8$

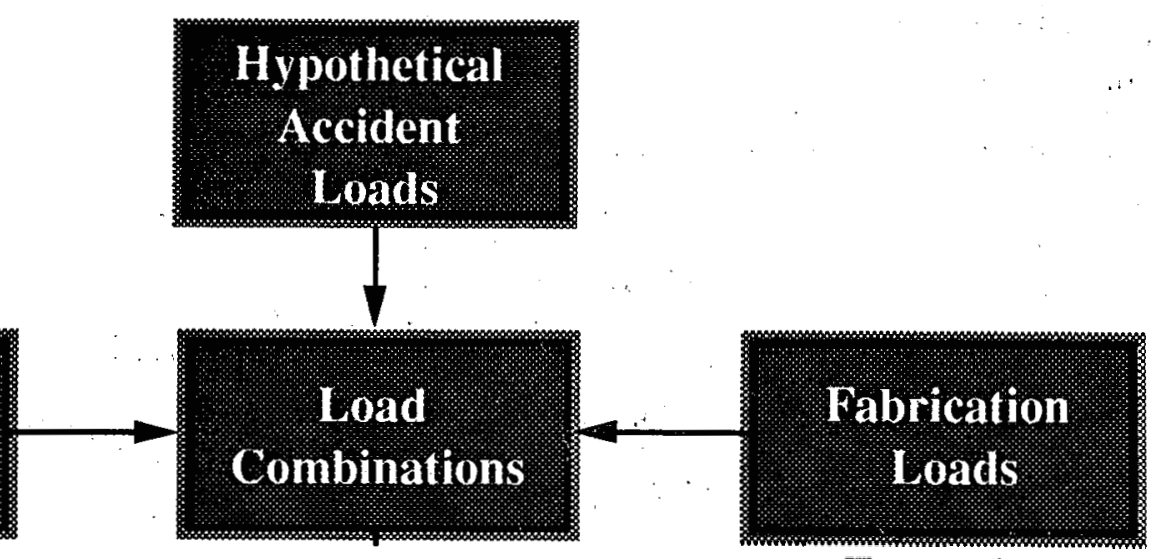

Examples:

Pressure

Bolt Loads

Thermal Gradients

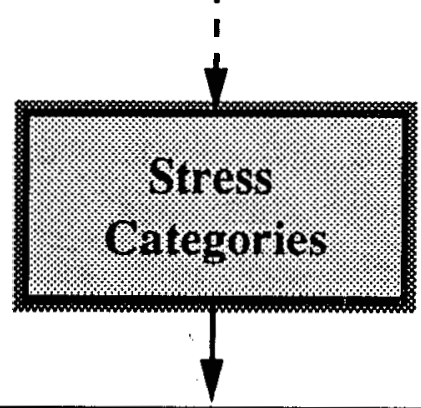

Examples:

Lead Pouring

Shrink Fits

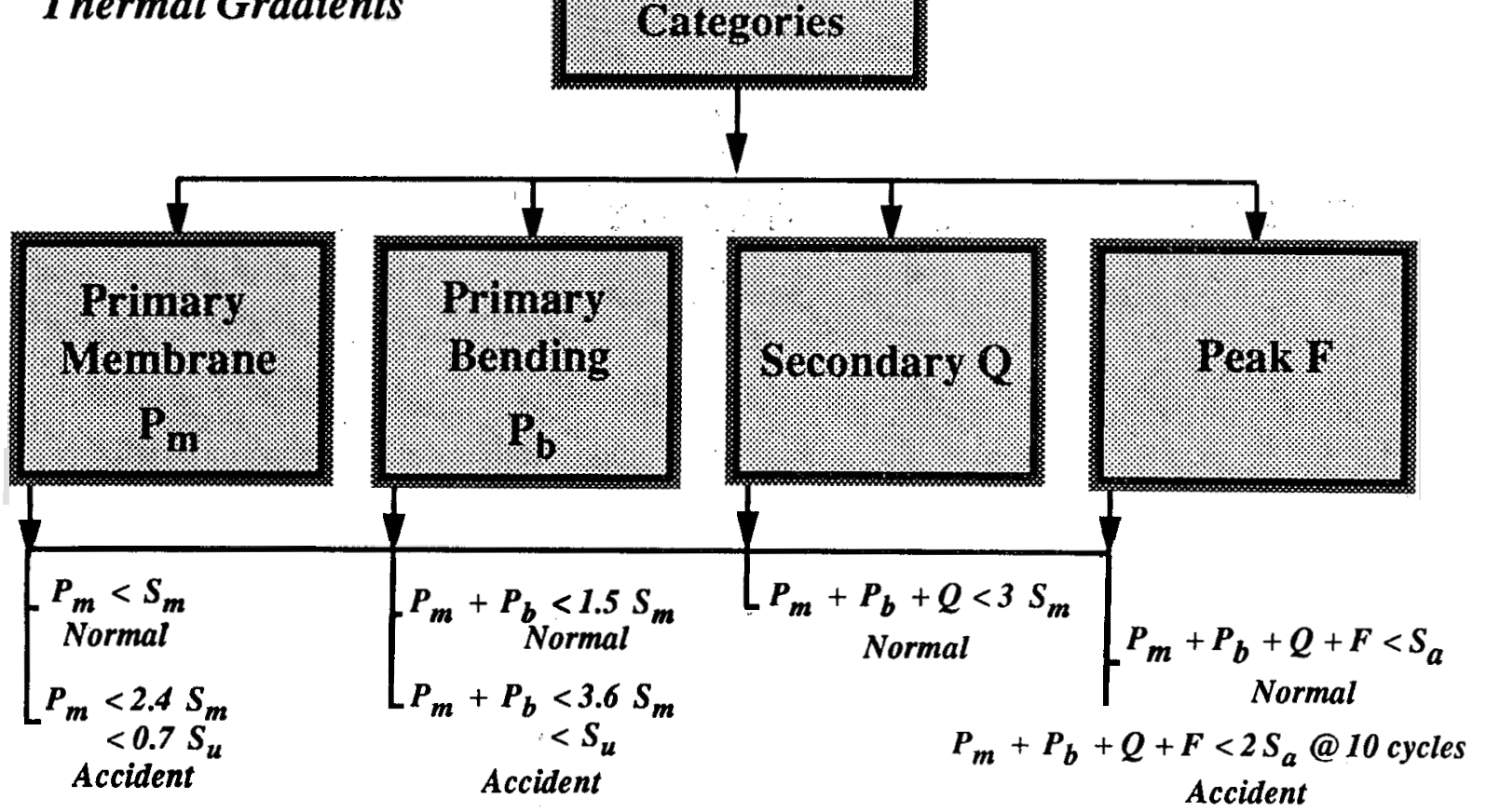

Fig. 3.1. Load combinations and stress intensity limits. 


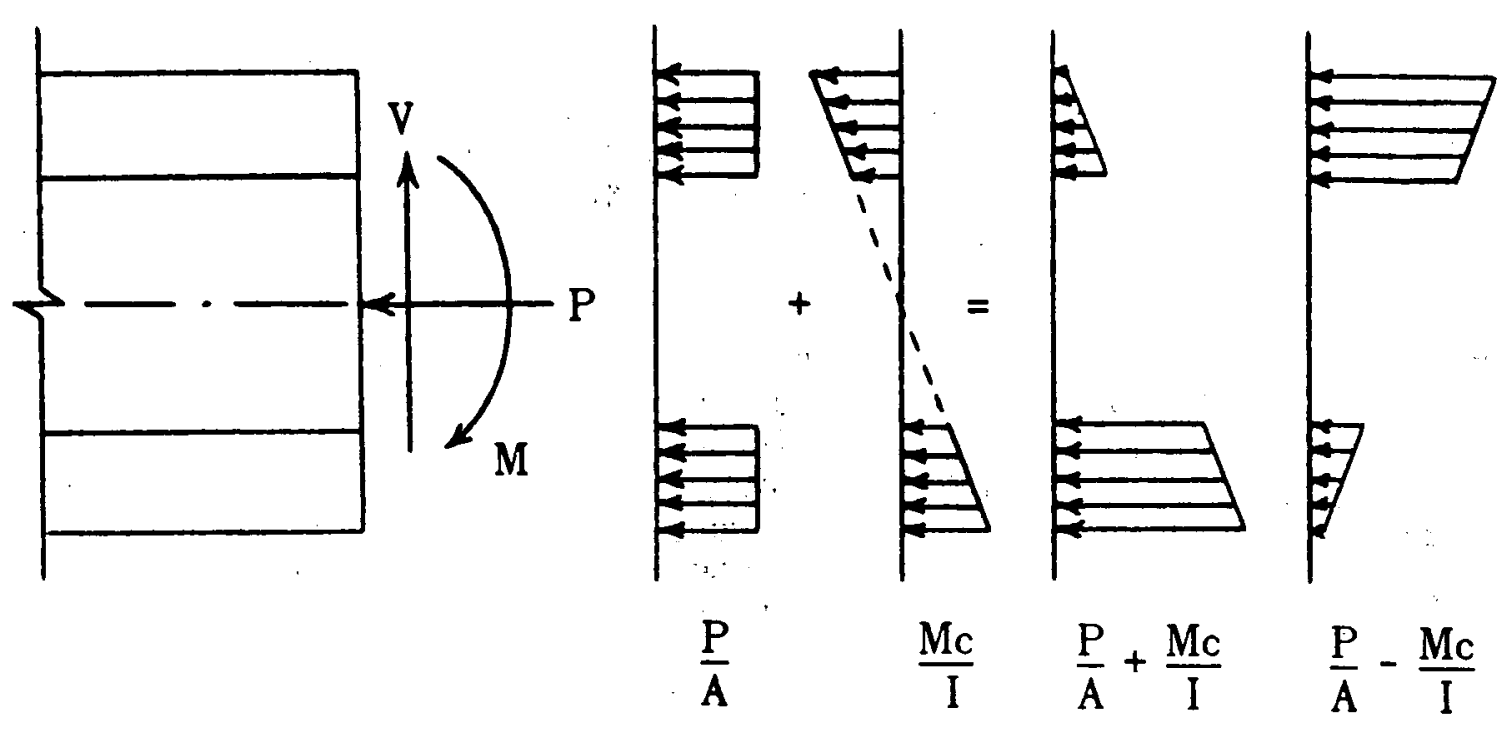

a. Solid Cask

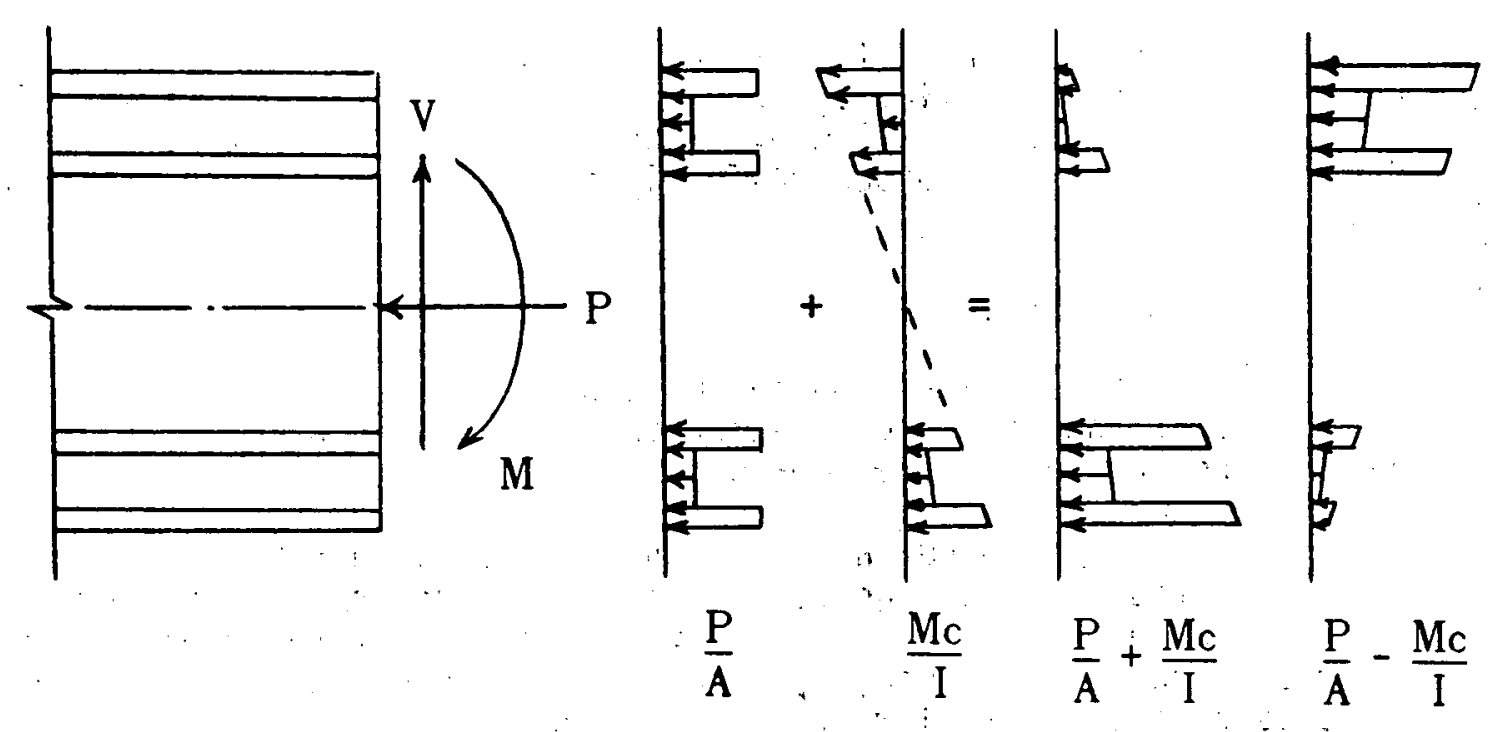

b. Laminated Cask

Fig. 3.2. Stress recovery for solid and laminated casks. 
shown in Fig. 3.2. For a large shell thickness or a very large moment compared to axial contribution, $P_{b}$ may become significant. In most instances, for a laminated cask, $P_{b}$ can be considered to be negligible, especially considering that the allowable for $P_{m}+P_{b}$ is fifty percent higher that that for $\mathrm{P}_{\mathrm{m}}$ alone.

The maximum shearing stress occurs at the center line of the cask cross section, where the moment contribution is zero. For a circular cross section, the maximum shearing stress is $2 \mathrm{~V} / \mathrm{A}$ for a solid cask, and is weighted for each material based on stiffness for a laminated cask. At this location, the primary membrane stress intensity can be determined from the principal stresses and the direction of the maximum principal stress will not be oriented along the cask axis as it was in the regions of the extreme fibers.

The loads on the cover plate due to cask impact are caused by the inertial load from the closure itself as well as the load imparted by the contents. Actually, the contents represent a secondary spring-mass system and, as such, may exhibit a dynamic response to impact. Since the basket system containing the contents can be quite complicated, it is not practical to model it in detail. As an alternative, it can be treated as a rigid mass with its inertial load acting in a quasi-static manner. In order to account for dynamic amplification, the resulting load is then multiplied by a factor of two as suggested by the Cask Designers Guide (Ref. 25, p.36).

There are two basic types of closures for casks for which the load distribution of the bolts will differ. The first is a two-part closure in which the sealing plug is protected by an outer closure as shown in Fig 3.3a. In this case, the bolts are loaded uniformly and the stress per bolt may be calculated from

$$
\sigma_{i}=a\left(W_{c}+2 W_{f}\right) / N A_{b},
$$

where $a$ is the maximum deceleration in units of $g, W_{c}$ is the weight of the cask closure, $W_{f}$ is the weight of the contents, $N$ is the number of bolts in. the inner closure, and $A_{b}$ is the area per bolt.

If the closure is exposed, as shown in Fig. 3.3b, there will be a complex pressure distribution at the edge of the cask when subjected to oblique impact. This can be modeled by assuming that the edge of the closure has a pinned boundary condition. Then, by assuming a rigid closure, the force per bolt can be calculated as follows (see Fig. 3.3b):

$$
\begin{aligned}
& N=\text { number of bolts } \\
& \theta=360 / N .
\end{aligned}
$$

Then

$$
I_{x x}=N r_{b}^{2} A_{b} / 2 \text { for } N>3 .
$$


Configuration

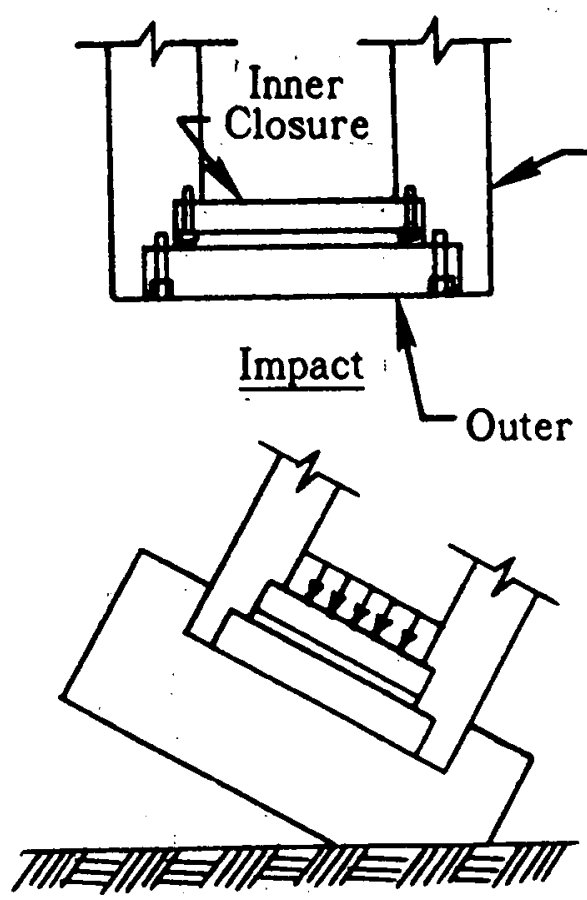

Model

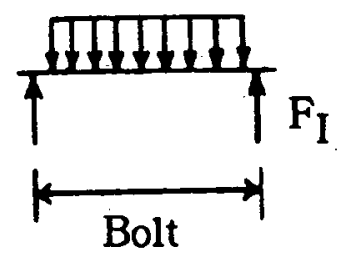

Diameter
Cask Shell

Closure<smiles>[TeH2]</smiles>

Configuration

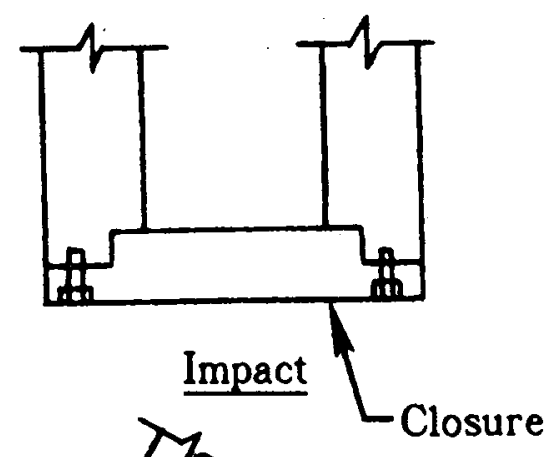

Limiter

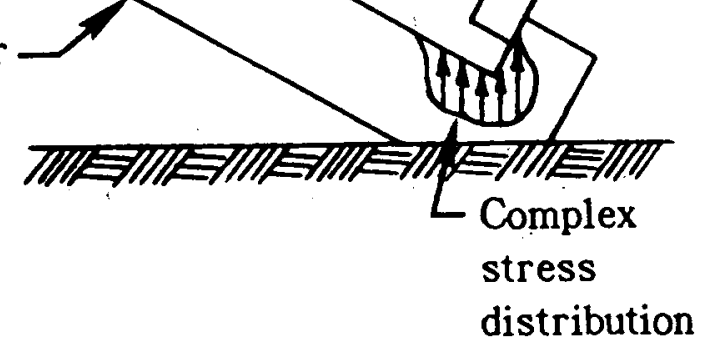

a. Protected Closure

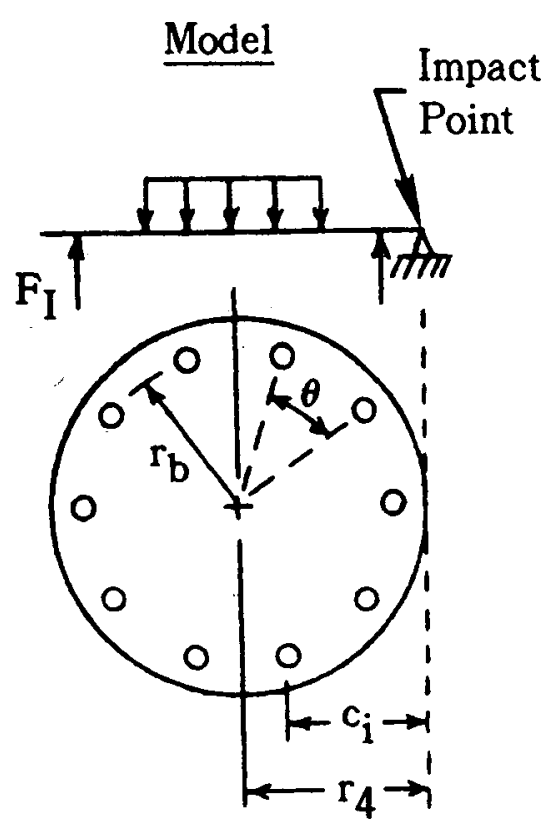

b. Exposed Closure

Fig. 3.3. Typical cask closure configurations and associated analytical models. 
This represents the moment of inertia through the centroid of the bolt group. About the base of the group, the moment of inertia becomes

$$
I_{a a}=I_{x x}+\mathrm{NA}_{b} r_{4}^{2},
$$

and the stress in bolt, $i$, becomes

$$
\sigma_{i}=M c_{i} / I_{a a}
$$

where

$$
M=a\left(W_{C}+2 W_{F}\right) r_{4},
$$

and

$$
\begin{aligned}
& c_{i}=r_{4}+r_{b}{ }^{*} \cos \alpha_{i} \\
& \alpha_{i}=(i-1)^{*} \theta, i=1, N .
\end{aligned}
$$

If the cask hits end-on, or nearly end-on, the reaction from the impact limiter will be distributed over the area of the end-cap and the bolt stresses should be nearly zero. 
References

1. U.S. Code of Federal Regulations, Title 49, Parts 170-180.

2. U.S. Code of Federal Regulations, Title 10, Part 71, "Packaging of Radioactive Material for Transport and Transportation of Radioactive Material under Certain Conditions", as revised in Federal Register, Vol. 48, No. 165, August, 1983.

3. U.S. Nuclear Regulatory Commission, "Design Criteria for the Structural Analysis of Shipping Cask Containment Vessels", Regulatory Guide 7.6, Rev. 1, March, 1978.

4. U.S. Nuclear Regulatory Commission, "Load Combinations for the Structural Analys is of Shipping Casks", Regulatory Guide 7.8, May, 1977.

5. Biggs, J.M., Introduction to Structural Dynamics, McGraw-Hi11, Inc., New York, 1964.

6. Gabrielson, V.K., Reese, R.T., "SHOCK Code User's Manual, A Computer Code to Solve the Dynamic Response of Lumped-Mass Systems", SCL-DR-6998, Sandia Laboratories, Livermore, CA, November, 1969.

7. Counts, J., Payne, J.B., "IMPAC2 - A Lumped-Mass Nonlinear Spring Computer Program to Analyze Type B Shipping Container Impact Problems," LA-6643-MS, Los Alamos Scientific Laboratory, January, 1977.

8. Cowper, G.R., "The Shear Coefficient in Timoshenko's Beam Theory", J. App. Mech., ASME, June, 1966, pp 335-340.

9. Roark, R. J. and Young, W. C., Formulas for Stress and Strain, McGraw-Hill Book Co., 1975.

10. Rubenstein, M. F., Structural Systems-Statics, Dynamics, and Stability, Prentice-Hall, Inc., 1970.

11. Thomson, W. T., Vibration Theory Applications, Prentice-Hall, Inc., 1965.

12. Clough, R. W., "The Finite Element in Plane Stress Analys is", Proceedings of the Second ASCE Conference on Electronic Computation, Pittsburgh, PA., 1960.

13. Courant, R., "Variational Methods for the Solution of Problems of Equilibrium and Vibrations", Bullet in of American Mathematical Society, 49, (1943).

14. Turner, M. J., Clough, R. W., Martin, H. C., and Topp, L. J., "Stiffness and Deflection Analys is of Complex Structures", Journal of Aeronautical Sciences, 23, 1956. 
15. Strang, G. and Fix, G. J., An Analys is of the Finite Element Method, Prentice-Hall, Inc., 1973.

16. Bathe, K.-J. and Wilson, E. L., Numerical Methods in Finite Element Analys is, Prentice-Ha11, Inc., 1976.

17. Tabarrok, B., "A Variational Principle for the Dynamic Analys is of Continua by Hybrid Finite Element Method", Internal Journal of Solids and Structures, 7, No. 3, 197.1 .

18. Shipley, S. A., Leistner, H. G. and Jones, R. E., "Elastic Wave Propagation--A Comparison Between Finite Element Predictions and Exact Solutions", Proceedings of the International Symposium on Wave Propagation and Dynamic Properties of Earth Materials, ATbuquerque, New Mexico (1967).

19. Kuhlemeyer, R. L. and Lysmer, J. "Finite Element Method Accuracy for Wave Propagation Problems", Journal of the Soil Mechanics and Foundations Division, Proceedings of the American Society of Civil Engineers, 99, SM5, 1973.

20. Charman, C. M. and Grenier R. M., "Large Deformation Inelastic Analys is of Impact for Shipping, Casks", Computer Methods in Applied Mechanics and Engineering, 33, (1982).

21. Hallquist, J. 0., DYNA3D User's Manual (Nonlinear Dynamic Analys is of Solids in Three Dimensions), Lawrence Livermore NationaT Laboratory, UCID-19592 (1982).

22. Belytschko, T., Holmes, N. and Mullen, R., "Explicit Integration -Stability, Solution Properties, Cost in Finite Element Arialysis of Transient Nonlinear Structural Behavior", ASME publication AMD-Vol. 14, 1975.

23. American Society of Mechanical Engineers, Boiler and Pressure Vessel Code, Sec. III, 1980.

24. American Society of Mechanical Engineers, Criteria of the ASME Boiler and Pressure Vessel Code for Design by Analysis in Sections III and VIII, Division ?, 1969 .

25. Shappert, L. B., et a1, "A Guide for the Design, Fabrication and" Operation of Shipping Casks for Nuclear Application", ORNL-NSIC-68, 0ak Ridge National Laboratory, Oak Ridge, TN, Feb., 1970. 
The following derivation is presented to illustrate how the force distributions in a slender rigid beam are determined for use in a quasi-static analysis.

Figure A.l shows a slender rigid beam subjected to an impact force, $F$. Applying Newton's second law to the center of gravity of the beam:

$$
\begin{aligned}
M \ddot{\bar{X}} & =F \sin \theta \\
\ddot{M} & =F \cos \theta \\
\ddot{\bar{Z}} & =-F(L / 2) \cos \theta
\end{aligned}
$$

where

$$
M=\text { mass of beam }=\mathrm{mL}
$$

$I$ = mass moment of inertia of beam about its center of gravity

$$
=M L^{2} / 12=\mathrm{mL}^{3} / 12
$$

$m=$ mass per unit length of beam $=M / L$

Substituting $(A-4)$ and $(A-5)$ into $(A-1),(A-2)$ and $(A-3)$,

$$
\begin{aligned}
& \ddot{\bar{X}}=F \sin \theta / \mathrm{mL} \\
& \ddot{\bar{Z}}=F \cos \theta / \mathrm{mL} \\
& \ddot{\theta}=-6 F \cos \theta / \mathrm{mL}^{2}
\end{aligned}
$$

Since the beam is assumed to be rigid, the longitudinal and normal accelerations at point $x$ (see Fig. A.I) can be expressed as:

$$
\begin{aligned}
\ddot{x} & =\ddot{\bar{x}}=F \sin \theta / m L \\
\ddot{n} & =\ddot{\bar{Z}}+(x-L / 2) \ddot{\theta} \\
& =F \cos \theta / \mathrm{mL}+(x-L / 2)\left(-6 F \cos \theta / \mathrm{mL}^{2}\right) \\
& =2 F \cos \theta(2 L-3 x) / \mathrm{mL}^{2}
\end{aligned}
$$

From the equilibrium of the beam in the longitudinal direction (Fig. A.2), the axial force $R$ can be derived:

$$
\begin{aligned}
& R-\{R+(d R / d x) d x\}=(m d x) \ddot{x}= \\
& d R / d x=-m \ddot{x}=-F \sin \theta / L
\end{aligned}
$$

Integrating from the top end (free end) to point $x$, 


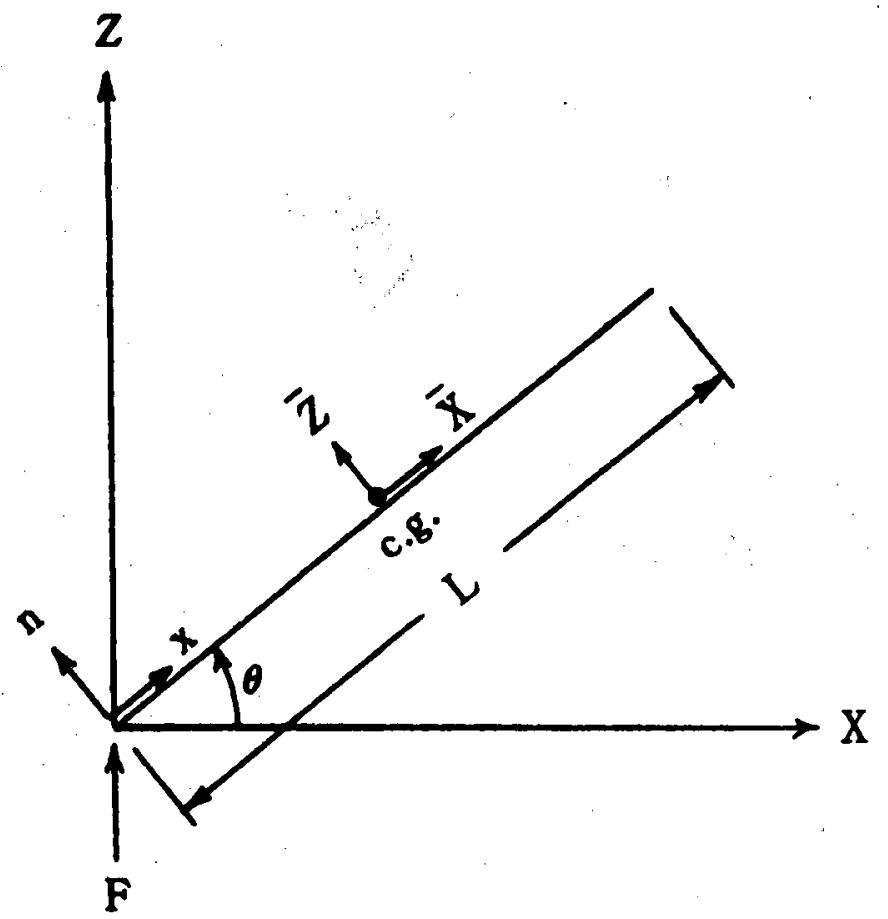

Fig. A.1. Coordinate systems for oblique drops of slender rigid beam. 


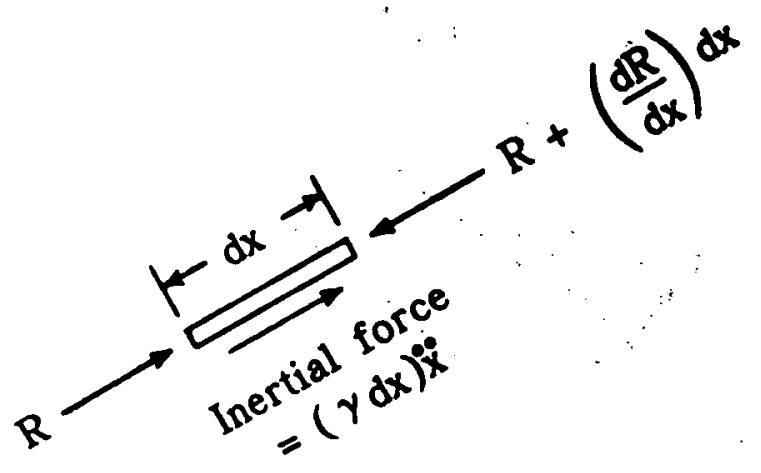

Fig. A.2. Equilibrium of slender rigid beam in the longitudinal direction. 


$$
R=\int_{L}^{x}(-F \sin \theta / L) d x=F \sin \theta(1-x / L)
$$

Similarly, from the equilibrium of the beam in the lateral direction (Fig. A.3), the shear force $V$ can be derived:

$$
\begin{aligned}
& V-\{V+(d V / d x) d x\}=(m d x) \ddot{n} \\
& d V / d x=-m \ddot{n}=2 F \cos \theta(3 x-2 L) / L^{2}
\end{aligned}
$$

Integrating from the top end to point $x$,

$$
\begin{aligned}
V & =\int_{L}^{x}\left\{2 F \cos \theta(3 x-2 L) / L^{2}\right\} d x \\
& =F \cos \theta\left(3 x^{2}-4 L x+L^{2}\right) / L^{2}
\end{aligned}
$$

Integrating the above formula, we can get an expression for the bending moment $M_{b}$ :

$$
\begin{aligned}
M_{b} & =\int_{L}^{x} V d x=\int_{L}^{x}\left\{F \cos \theta\left(3 x^{2}-4 L x+L^{2}\right) / L^{2}\right\} d x \\
& =F \cos \theta\left(x^{3}-2 L x^{2}+L^{2} x\right) / L^{2}
\end{aligned}
$$




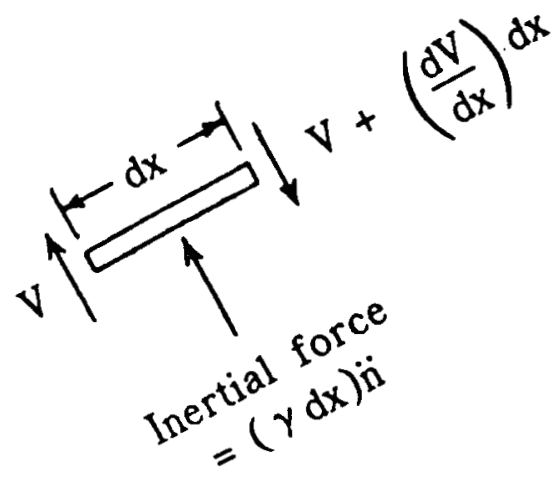

Fig. A.3. Equilibrium of slender rigid beam in the lateral direction. 


\section{NAC FOAM 335 \\ $(7.77)$ \\ U.S. NUCLEAR REgULATORY COMMISSION \\ BIBLIOGRAPHIC DATA SHEET}

4. TITLE AND SUBTITLE (Ada Volume No., if eppropriste)

Methods for Impact Analysis of Shipping Containers

7. AUTHORIS)

T.A. Nelson and R.C. Chun

9. PERFORMING ORGANIZATION NAME AND MAILING ADDRESS (Include Zip Code)

Lawrence Livermore National Laboratory

P.O. Box 808, L-197

Livermore, CA 94550

12. SPONSORING ORGANIZATION NAME AND MAILING ADDRESS (Include Zip Code)

Division of Safety Technology

Office of Nuclear Material Safety and Safeguards

U.S. Nuclear Regulatory Comission

Washington, D.C. 20555
1. REPORT NUMBER (Assigned bY DDC)

NUREG/CR-3966

UCID-20639

2. (Leave blank)

3. RECIPIENT'S ACCESSION NO.

5. DATE REPORT COMPLETED

\begin{tabular}{l|l}
\hline MONTH & YEAR
\end{tabular}

October 1987

DATE REPORT ISSUED

MONTH

November

YEAR

6. (Leave b/ank)

8. (Leave blank)

10. PROJECT/TASK/WORK UNIT NO.

11. CONTRACT NO

FIN A029!

13. TYPE OF REPORT

PERIOD COVERED (Inclusive dates)

Technical

15. SUPPLEMENTARY NOTES

14. (Leave blank)

16. ABSTRACT 200 words or less) This report reviews methods for performing impact stress analyses of shipping containers used to transport spent fuel. Three methods are discussed: quasi-static, dynamic lumped parameter and dynamic finite element. These methods are used by industry for performing impact analyses for Safety Analysis Reports.

The approach for each method is described including assumpitions and limitations and modeling considerations. The effects of uncertainties in the modeling and analyzing of casks are identified. Each of the methods uses linear elastic structural analysis principles. Methods for interfacing impact stresses with the design and load combinations criteria specified in Regulatory Guides 7.5 and 7.8 are outlined.

The quasi-static method is based on D'Alembert's principle to substitute equivalent static forces for inertial forces created by the impact. The lumped parameter method is based on using a discrete number of stiffness elements and masses to represent the cask during impact. The dynamic finite element method uses finite element techniques combined with time integration to analyze the cask impact. Each of these methods car provide an acceptable means, within certain limitations, for analyzing cask impact on unyielding. surfaces.

17. KEY WORDS AND DOCUMENT ANALYSIS

impact analysis

spent fuel

quasi-static method

dynamic lumped parameter method

\section{7a. DESCRIPTORS}

dynamic finite element method

17b. IDENTIFIERS/OPEN-ENDED TERMS

18. AVAILABILITY STATEMENT

Unlimited

\begin{tabular}{|l|l|}
\hline $\begin{array}{l}\text { 19. SE CURITY CLASS (This report) } \\
\text { UnClassified }\end{array}$ & 21. NO. OF PAGES \\
\hline $\begin{array}{c}\text { 20. SECURITYCLASS (This poge) } \\
\text { UnClaSSified }\end{array}$ & $\begin{array}{c}\text { 22. PRICE } \\
\text { S }\end{array}$ \\
\hline
\end{tabular}

NAC. FORM $335(7.77)$

औU. S. COVERNMENT PRINTINC OFFICE: 1987-202-292:60276 


\section{NOTICE}

This report was prepared as an account of work sponsored by an agency of the United States Government. Neither the United States Government nor any agency thereof, or any of their employees, makes any warranty, expressed or implied, or assumes any legal liability of responsibility for any third party's use, or the results of such use, of any information, apparatus. product or process disclosed in this report, or represents that its use by such, third party would not infringe privately owned rights.

\section{Availability of Reference Materials Cited in NRC Publications}

Most documents cited in NRC publications will be available from one of the following sources:

1. The NRC Public Document Room, 1717 H Street, N.W. Washington, DC 20555

2. The NRC/GPO Sales Program, U.S. Nuclear Regulatory Commission, Washington, DC 20555

3. The National Technical Information Service, Springfield..VA 22161

Although the listing that follows represents the majority of documents cited in NRC publications, it is not intended to be exhaustive.

Referenced documents available for inspection and copying for a fee from the NAC Public Document Room include NRC correspondence and ir.ternal NRC memoranda; NRC Office of Inspection and Enforcement bulletins, circulars, information notices, inspection and investigation notices: Licensee Event Reports; vendor reports and correspondence; Commission papers; and applicant and licensee documents and correspondence.

The following documents in the NUREG series are available for purchase from the NAC/GPO Sales Program: formal NRC staft and contractor reports. NRC.sponsored conference proceedings, and NRC booklets and brochures. Also available are Regulatory Guides, NRC regulations in the Code of Federal Regulations, and Nuclear Regulatory Commission Issuances.

Documents available from the National Technical Information Service include NUREG series reports and technical reports prepared by other federal agencies and reports prepared by the Atomic Energy Commission, forerunner agency to the Nuclear Regulatory Commission.

Documents available from public and special technical libraries include all open literature items. such as books, journal and periodical articles, and transactions. Federal Register notices. federal and state legislation. and congressional reports can usually be obtained from these libraries.

Documents such as theses, dissertations, foreign reports and translations, and non.NAC conference proceedings are available for purchase from the organization sponsoring the publication cited.

Single copies of NRC draft reports are available free upon written request to the Division of Technical information and Document Control, U.S. Nuclear Regulatory Commission. Washington, DC 20555.

Copies of industry codes and standards used in a substantive manner in the NRC regulatory process are maintained at the NAC Library, 7920 Norfolk Avenue. Bethesda. Maryland, and are available there for reference use by, the public. Codes and standards are usually copyrighted and may be purchased from the originating organization or. if they are American National Standards, from the American National Standards Institute. 1430 Broadway. New York. NY 10018. 